\section{ANNUAL Further}

Click here for quick links to Annual Reviews content online, including:

- Other articles in this volume

- Top cited articles

- Top downloaded articles

- Our comprehensive search

\title{
On the Mechanistic Origins of Toughness in Bone
}

\section{Maximilien E. Launey, ${ }^{1}$ Markus J. Buehler, ${ }^{2}$ and Robert O. Ritchie ${ }^{1,3}$}

Annu. Rev. Mater. Res. 2010. 40:25-53

First published online as a Review in Advance on February 26, 2010

The Annual Review of Materials Research is online at matsci.annualreviews.org

This article's doi:

10.1146/annurev-matsci-070909-104427

Copyright (c) 2010 by Annual Reviews. All rights reserved

1531-7331/10/0804-0025\$20.00

\author{
${ }^{1}$ Materials Sciences Division, Lawrence Berkeley National Laboratory, Berkeley, \\ California 94720; email: MELauney@lbl.gov, RORitchie@lbl.gov \\ ${ }^{2}$ Department of Civil and Environmental Engineering, Massachusetts Institute of Technology, \\ Cambridge, Massachusetts 02139; email: mbuehler@MIT.EDU \\ ${ }^{3}$ Department of Materials Science and Engineering, University of California, Berkeley, \\ California 94720
}

\section{Key Words}

fracture, deformation, mechanisms, length scales

\begin{abstract}
One of the most intriguing protein materials found in nature is bone, a material composed of assemblies of tropocollagen molecules and tiny hydroxyapatite mineral crystals that form an extremely tough, yet lightweight, adaptive and multifunctional material. Bone has evolved to provide structural support to organisms, and therefore its mechanical properties are of great physiological relevance. In this article, we review the structure and properties of bone, focusing on mechanical deformation and fracture behavior from the perspective of the multidimensional hierarchical nature of its structure. In fact, bone derives its resistance to fracture with a multitude of deformation and toughening mechanisms at many size scales ranging from the nanoscale structure of its protein molecules to the macroscopic physiological scale.
\end{abstract}




\section{INTRODUCTION}

By manipulating combinations of minerals and organic polymers into hierarchical structures spanning multiple length scales, nature has developed a wide range of hybrid materials with specific properties matched to function (1-4). Indeed, these biological systems represent an inexhaustible source of inspiration to materials scientists in offering potential solutions for the development of new generations of structural materials (5-7). Nature's key role here is in the complex hierarchical structuring of the materials (8-12) that, unlike engineering materials that are fabricated according to specific requirements, are grown using the principles of biologically controlled self-assembly (2). The act of growing rather than fabricating leads to the possibility of dynamic strategy, which allows for flexibility at all levels. The concept of multiscale hierarchical structures, where the microstructure at each level is adapted to local needs (13), allows for the adaptation and optimization of a material's form and structure at each level of hierarchy to meet specific functions $(11,12,14)$. Indeed, the complexity and symbiosis of structural biological materials have generated enormous interest of late, primarily because these composite biological systems exhibit mechanical properties that are invariably far superior to those of their individual constituents (15).

One of the most intriguing and complex materials found in nature is bone. Like any other biological systems, bone is a highly hierarchical composite material composed primarily of assemblies of collagenous protein molecules, water, and mineral nanoparticles made of carbonated hydroxyapatite, forming an extremely tough, lightweight, adaptive, and multifunctional material. Bone is often stereotyped as simply a protective and supportive framework for the body; although it does perform this function, it is actually a very dynamic organ that is constantly remodeling and changing shape to adapt to the daily forces placed upon it. Like all natural materials, its mechanical properties are determined by its structure $(2,15,16)$, which in turn is motivated by its (primarily mechanical) function $(17,18)$. The adaptation of compact bone to its mechanical environment includes both alteration of its shape and adaptation of its internal structure, i.e., its material properties. Long bones, such as the femur and the tibia, provide stability against bending and buckling. Short bones, e.g., vertebrae, provide stability against compression, whereas platelike bones such as those forming the skull protect vital organs. The diversity of structures within this family reflects the fine-tuning or adaptation of the structure to its function.

In addition, a remarkable property of bone is its well-known capacity of self-repair (19). In bone, the combination of growth and remodeling (resorption and replacement of old material) occurs via specialized cells (osteoclasts) that are permanently removing material while other cells (osteoblasts) are depositing new tissue. This continuous remodeling allows for structural adaptation to changing external conditions, as well as the removal and replacement of damaged material $(16,20,21)$. Unfortunately, excessive remodeling and other aging-related changes to the musculoskeletal system increase susceptibility to bone fracture (22). In the case of the elderly, such changes are critical because the consequent fractures can lead to significant mortality. Although a number of extraosseous variables, such as loading regime, incidence of traumatic falls, and prior fractures, are involved, the bone tissue itself deteriorates with age (22-24). A primary factor here is bone quality, which is a loosely defined term used to describe some, but probably not all, characteristics of the bone matrix nano- and microstructure that can influence mechanical properties such as stiffness (resistance to elastic deformation), strength (resistance to plastic deformation), and toughness (resistance to fracture).

Traditional thinking on the deterioration of bone with age has focused on bone quantity as a predictor of such fracture risk. Bone quantity is described by the bone mass or bone mineral density (BMD), defined as the amount of bone mineral per unit cross-sectional area. For example, the elevation in bone-remodeling activity, concurrent with menopause in aging women, can lead to 
osteoporosis, a condition of low bone mass associated with an increased risk of fracture. However, although bone mass can explain some of the fracture risk, there is now mounting evidence that low BMD alone is not the sole factor responsible for the aging-induced fracture risk. Specifically, a landmark study by Hui et al. (22) revealed a roughly tenfold increase in fracture risk with aging that was independent of BMD. This result and the concurrent realization that bone mass alone cannot explain the therapeutic benefits of antiresorptive agents in treating osteoporosis (24) have reemphasized the necessity for understanding the factors that control bone quality. Indeed, there has recently been a renewed interest in the strength and fracture properties of bone, motivated by the notion that an appropriate assessment of bone quality could potentially be used to predict the risk of bone fracture.

As there is still only limited understanding of the physics-based mechanisms of bone fracture and how they relate to its hierarchical, multidimensional structure $(25,26)$, one vital question that is paramount is the origin of bone's fracture resistance in relation to these structural length scales. To understand the toughness of bone and to discern the roles of the observed toughening mechanisms, it is pertinent to note that fracture resistance is a multiple-scale process, with each level of structural hierarchy adapted to provide optimal toughness. Traditionally, toughness has been thought of as the ability of a material to dissipate deformation energy without propagation of a crack. However, fracture is actually the result of a mutual competition of $(a)$ intrinsic damage mechanisms ahead of a crack tip that promote cracking and $(b)$ extrinsic shielding mechanisms, mainly behind the tip, that impede cracking $(27,28)$. Intrinsic toughening mechanisms increase the microstructural resistance to crack initiation and growth, as exemplified by the role of plasticity ahead of the crack tip in metals. Extrinsic toughening involves microstructural mechanisms that act primarily behind the crack tip to inhibit crack growth by effectively reducing the crack-driving force actually experienced at the crack tip, as illustrated by crack-tip shielding mechanisms such as crack bridging $(29,30)$. A discussion on how the fracture toughness can be quantitatively measured in light of these different classes of mechanisms is presented in the Appendix.

In this review, we describe the mechanistic roles that the multilevel structural constituents of bone play in affecting its resistance to fracture, in terms of both the initiation and the subsequent propagation of cracks. We show that the toughness of bone is a result of a suite of potent extrinsic (shielding) mechanisms, specifically crack deflection and bridging, acting primarily at the micro length scales and above (typically at dimensions above $\sim 1 \mu \mathrm{m})(31)$, coupled with an additional role of intrinsic toughening due to the significant plasticity in the material generated at multiple length scales (although primarily at dimensions below $\sim 1 \mu \mathrm{m}$ ). Whereas the extrinsic shielding mechanisms affect only the propagation of cracks (as assessed by the crack-resistance curve, or R-curve), the plasticity mechanisms in bone affect both crack initiation and growth and include a number of inelastic, nonrecoverable deformation mechanisms, such as local collagen fibrillar shearing and viscoplasticity at submicrometer scales and microcracking at somewhat coarser scales (32).

\section{HIERARCHICAL STRUCTURE OF BONE}

The structure of bone can be viewed as cascaded arrangements of building blocks at defined length scales (Figure 1). These building blocks form a hierarchical structure that controls its properties, e.g., deformation and toughness $(25,26,33)$. Bone tissue can be either trabecular (spongy) or cortical (compact). Trabecular bone, also known as cancellous bone, fills the insides of many bones; it is spongy with struts of order 100-300 $\mu \mathrm{m}$ in diameter. This review focuses primarily on cortical bone, which is the dense bone that is found at the outer surfaces of all bones. The cortical bone shell can reach a thickness of between several tenths of a millimeter (in vertebrae) and several millimeters (in the mid-shaft of long bones). Structurally, the basic building blocks 
Figure 1

Hierarchical structure of bone showing seven levels of hierarchy.

The macroscale arrangements of bones are either compact/ cortical (dense material found at the surface of all bones) or spongy/cancellous (foam-like material whose struts are some $100 \mu \mathrm{m}$ thick).

Compact bone is composed of osteons that surround and protect blood vessels. Osteons have a lamellar structure. Each individual lamella is composed of fibers arranged in geometrical patterns. These fibers are the result of several collagen fibrils, each linked by an organic phase to form fibril arrays. Each array makes up a single collagen fiber. The mineralized collagen fibrils are the basic building blocks of bone. They are composed of collagen protein molecules (tropocollagen) formed from three chains of amino acids.

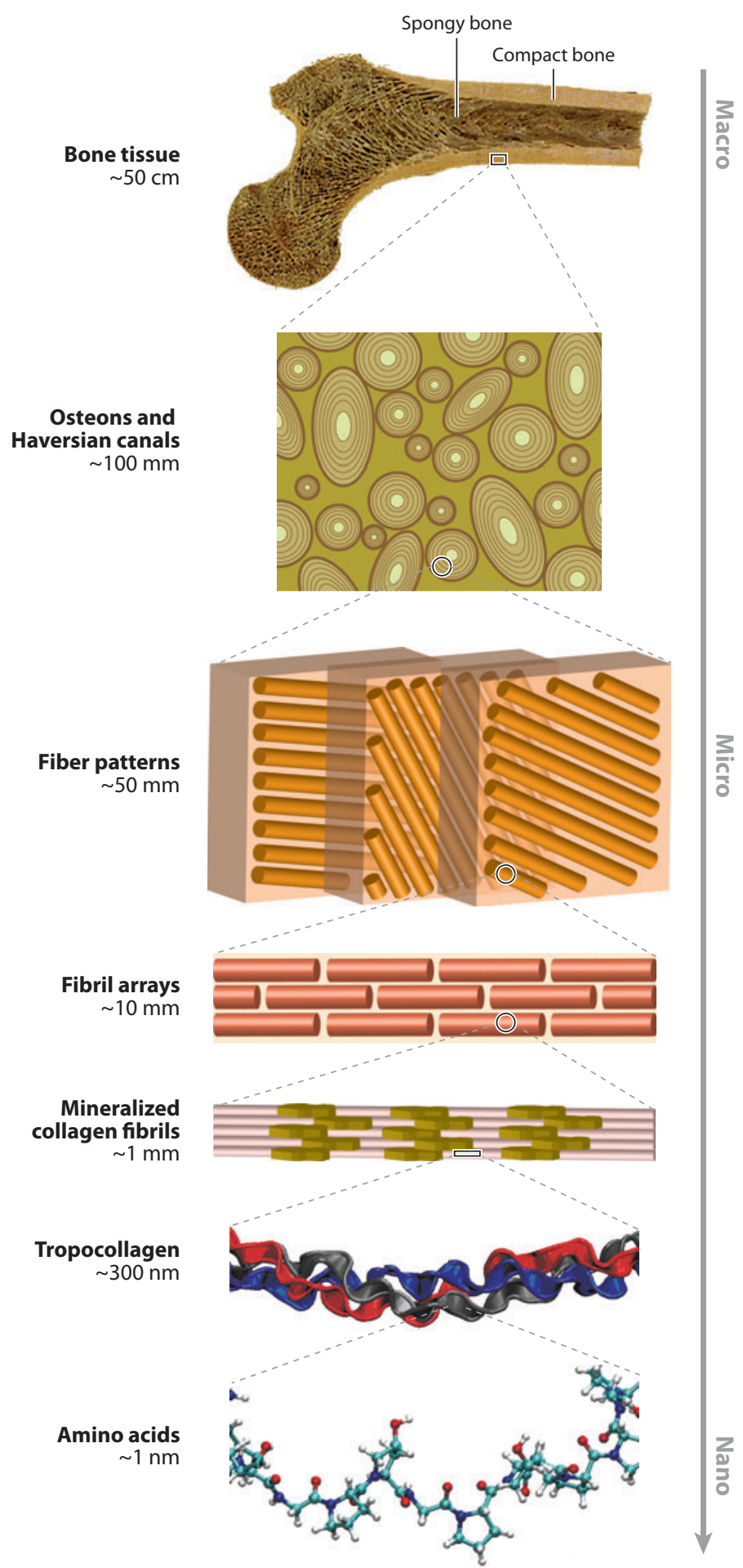


of such bone are an organic matrix (90\% type I collagen, 10\% amorphous ground substance) and a mineral phase (calcium phosphate-based hydroxyapatite). However, bone composition and structure are not invariant; they vary with factors such as skeletal site, age, sex, physiological function, and mechanical loading, making bone a very heterogeneous structure. Different bones grow at different rates, and the kind of primary bone laid down depends on the rate of accretion. The mineral content varies substantially from bone to bone; antlers have the lowest mineral content in the bone family (55-60 wt\%), and whale fins have the highest mineral content ( $90 \%$ $\mathrm{wt} \%$ ) (16). The main determinant of mechanical properties is generally the amount of mineral in the tissue $(16,18)$. Accordingly, different bones have different mechanical properties depending on the growth, structure, and adaptation, all of which are interconnected to serve a specific function.

Figure 2 shows typical structures found at a lower hierarchical level in cortical bone. Cortical bone is a particularly neatly arranged laminar bone. Blood vessels are more irregularly disposed or do not form a network, and the laminar arrangement gives way to one in which the blood vessels anatomize in three dimensions, each surrounded by more or less concentric layers of lamellar bone; these structures are called primary osteons. They resemble secondary osteons, or Haversian systems, which provide the basis for the growth of new bone. The microstructures of two different types of compact bone, i.e., primary bone in elk antler and secondary bone in adult human bone, are compared in Figure $\mathbf{2 b}$, . Antlers are young bones that undergo limited remodeling and are composed predominantly of primary osteons (34) that contain vascular channels $(15-25 \mu \mathrm{m}$ in diameter) surrounded by concentric bone lamellae (Figure $2 c$ ). Secondary osteon remodeling

a

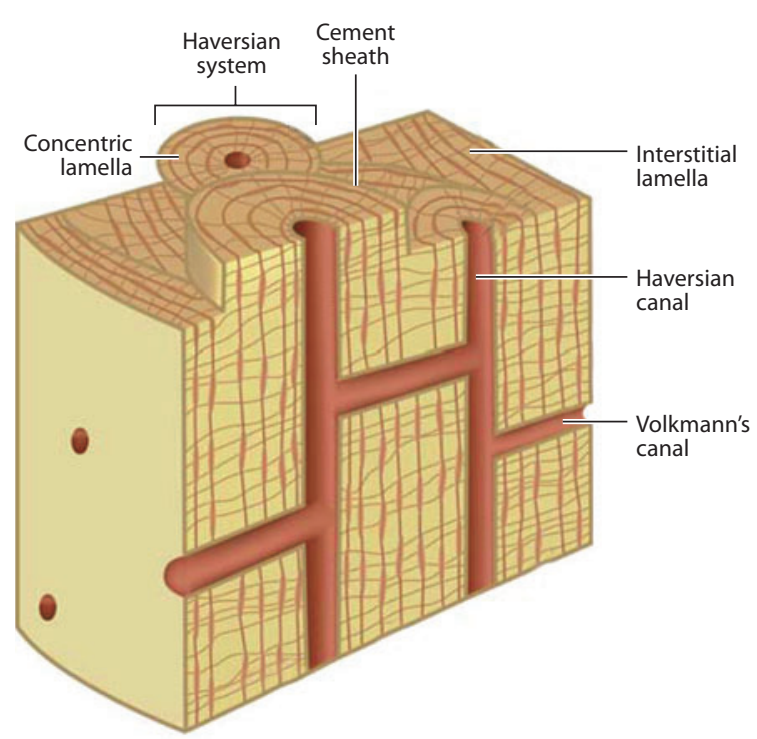

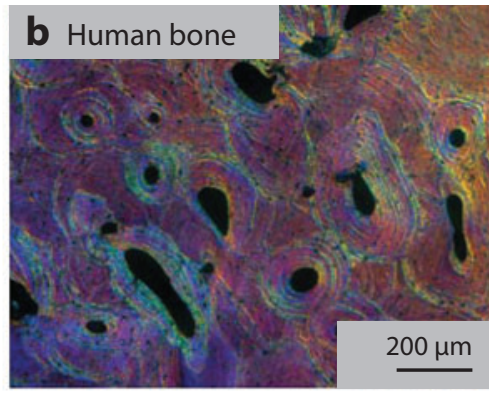

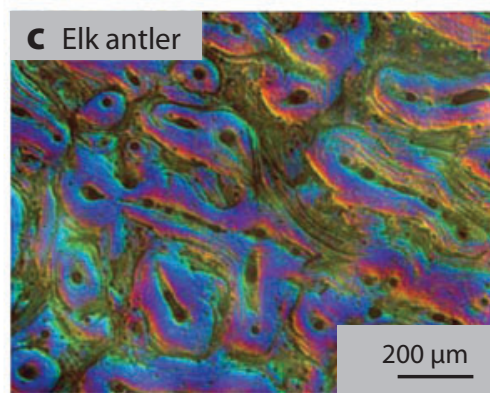

Figure 2

(a) Schematic diagram of the structure of cortical bone showing the pertinent microstructural features. $(b, c)$ Microstructure of $(b)$ secondary and $(c)$ primary bone. Differential interference contrast (Nomarski) micrograph of a transverse section of compact (cortical) bone of $(b)$ human humerus and $(c)$ elk antler. The main distinction between primary and secondary bone is that primary osteons do not have cement lines because they are not the product of bone remodeling; however, the interfaces of the primary osteons in antler are thick hypermineralized regions. Primary osteons have smaller vascular channels and fewer lamellae than do secondary osteons. 
arises in response to mechanical stress. In human bones, the whole remodeling process takes approximately two to four months (16). Because antlers do not sustain mechanical loads during the growth process and are used only in sporadic combat for one to two months before shedding, secondary osteons do not develop under these conditions. The entire primary osteons are $100 \mu \mathrm{m}$ to $200 \mu \mathrm{m}$ in diameter. In comparison, human bone is a secondary (replacement) bone that is the product of resorption of previously existing bone tissue and the deposition of new bone in its place. This process results in the formation of secondary osteons that have central vascular channels (Haversian canals) some $50 \mu \mathrm{m}$ to $90 \mu \mathrm{m}$ in diameter (Figure $\mathbf{2 b}$ ). These channels are surrounded by a series of concentric lamellae containing osteocytes arranged in a nominally circular fashion. The entire secondary osteons (or secondary Haversian systems) are approximately $200 \mu \mathrm{m}$ to $300 \mu \mathrm{m}$ in diameter. In antler bone (Figure $2 c$ ), a hypermineralized region surrounding the primary osteons (34) is present, whereas in human bone (Figure $\mathbf{2} \boldsymbol{b}$ ), a thin mineralized region, the cement line (35), surrounds the secondary osteons. As prominent sites for microcracking, both microstructural features have strong implications for fracture behavior and bone toughness $(36,37)$.

Although a diversity of structural motifs exists between bone tissues at different microstructural length scales (26), the most common motif in bone is the lamellar unit $(38,39)$. As mentioned above, osteons (lamellar bone) have a lamellar structure with adjacent lamellae some 3-7 $\mu \mathrm{m}$ thick $(40,41)$. Each of these lamellae consists of a series of fibril layers oriented at different angles of the osteon axis (Figure 1). Several studies $(38,39)$ have suggested the existence of a plywood-type structure, where the fibrils rotate not only with respect to the osteon axis but also around their own axis across the width of the lamella. Indeed, novel measurement methods combining synchrotron $\mathrm{X}$-ray texture measurements and scanning of thin sections of secondary osteons $(42,43)$ indicate that each lamella consists of a series of fibril layers oriented at different angles to the osteon axis, and angles are always positive.

At the nanoscale level of hierarchy, each individual fiber is composed of an array of mineralized collagen fibrils. The mineralized collagen fibril, which is roughly $100 \mathrm{~nm}$ in diameter and $\sim 5-$ $10 \mu \mathrm{m}$ or more in length, is the basic building block of the bone matrix. The fibrils consist of an assembly of 300-nm-long and 1.5-nm-thick collagen molecules, which are deposited by the osteoblasts into the extracellular space and then self-assemble into fibrils. The collagen fibrils are filled and coated by tiny mineral crystals of hydroxyapatite that assemble in the gap between collagen fibrils, and the fibrils become mineralized as the bone tissue grows and matures. These crystals are mainly flat and are arranged mostly parallel to each other and to the long axis of the collagen fibrils in the bone composite in a regularly repeating, staggered arrangement (44, 45 ). In bone tissue from several different mammalian and nonmammalian species, bone mineral hydroxyapatite crystals are very small, with a thickness of $1.5-4.5 \mathrm{~nm}(33,46-51)$ (with implications for hydroxyapatite fracture behavior, as discussed in Reference $52^{1}$ ). At the lowest dimension level, the collagen fibrils are formed by staggered arrays of tropocollagen molecules, each built from three polypeptides arranged in a $300-\mathrm{nm}$-long triple-helical nanorope geometry and stabilized by hydrogen bonding (H-bonding) between residues (53-55). Every third residue in each of these molecules is a glycine amino acid, and approximately one-fourth of the tropocollagen molecule consists of proline and hydroxyproline $(56,57)$.

Collagen is one of the most abundant proteins on Earth and is arguably the most important structural protein in biology. As we discuss below, the soft collagen gives bone its elasticity and

\footnotetext{
${ }^{1}$ With their high elastic modulus ( $\sim 100 \mathrm{GPa}$ ), hydroxyapatite crystals are responsible for the stiffness of bone. However, to offset the extreme brittleness of hydroxyapatite (which has a fracture toughness of less than $1 \mathrm{MPa} \sqrt{\mathrm{m}}$ ), the mineral crystals are nanoscale in size such that their (Griffith) fracture stress is very high, i.e., at nanoscale dimensions, they are insensitive to flaws (52).
} 
the ability to dissipate energy under mechanical deformation. Notably, even minute structural changes in a collagen molecule's architecture can have severe consequences for macroscale tissue behavior, as is evident in genetic bone diseases.

\section{INTRINSIC TOUGHENING (DEFORMATION) MECHANISMS}

The mechanical properties of the constituents of bone largely control its strength and plasticity. However, these properties are strongly dependent on the scale of observation. Recent experimental and theoretical studies have provided new insight into the mechanisms underlying this behavior, most notably through the use of advanced instrumentation that has permitted the examination of bone properties at ever-decreasing length scales, e.g., transmission electron and X-ray microscopy, atomic force microscopy, and Raman spectroscopy, as well as bottom-up multiscale simulation modeling. Together, these studies suggest that permanent deformation (plasticity) in bone is the result of concurrent multiple deformation mechanisms that are active predominantly at submicrometer levels (Figure 3). However, even though individual mechanisms have been identified, there is still no integrated model of plastic deformation in bone. Plasticity at molecular scales is particularly challenging to identify. Whereas it has been shown that the breaking of H-bonds is a crucial mechanism of large and permanent deformation of protein molecules, fibrils, and fibers, this mechanism is reversible when applied forces are removed (see Figure $\mathbf{4}$ for an illustration of how H-bonds break as forces are applied to a collagen protein molecule). The force required to break these bonds is highly dependent on the deformation rate (timescales), which provides a mechanism to dissipate energy under rapid loading (58-60). Indeed, such breaking of H-bonds can be regarded as a viscoelastic effect. This suggests that plastic deformation in bone must also involve larger-scale mechanisms such as intermolecular sliding, which would not be reversible unless remodeling of bone occurred. In general, the salient deformation mechanisms in bone are associated with different structural levels (Figure 3), as described below.

\subsection{Hydrogen-Bond Breakage in Pure Collagen: Molecular Uncoiling}

The basic deformation mechanism of individual collagen molecules is molecular stretching and unwinding due first to entropic and then to energetic mechanisms that involve breaking of $\mathrm{H}$ bonds (Figure 4). In collagen fibrils, molecular stretching competes with intermolecular sliding and breaking of weak and strong bonds between tropocollagen molecules. These sliding motions provide the basis for large plastic strains without catastrophic brittle failure. Severe mechanical tensile loading of collagen is significant under physiological conditions in various related tissues, representing one of its key performance features, as shown by its ability to stretch up to $50 \%$ tensile strain before breaking while reaching force levels of more than $10 \mathrm{nN}$ (per molecule) or 10-20 GPa stress (obtained by normalization of the force by the cross-sectional area of the molecule) (6165). Figure 5 shows a tensile test of a tropocollagen molecule for deformation up to $40 \%$ strain. The plot also shows the progression of H-bond breaking as the molecule unravels (65). H-bond breakage at $10 \%$ to $20 \%$ strain provides one of the major mechanisms that mediate the deformation of collagen fibrils; it is a reversible process and may thus provide a means to dissipate energy through large-deformation behavior of the soft-collagen bone matrix. The specific structure of intermolecular cross-links thereby plays a crucial role in defining the particular deformation paths. Aged collagen tends to show a high cross-link density, whereas young collagen features few crosslinks. The larger the cross-link density, the lower is the material's ability to dissipate energy without failure. At large cross-link densities, collagen fibrils tend to involve molecular fracture and breaking of cross-links (66), leading to increasingly brittle material behavior. This is certainly one factor associated with the increased fracture risk in older bone. 


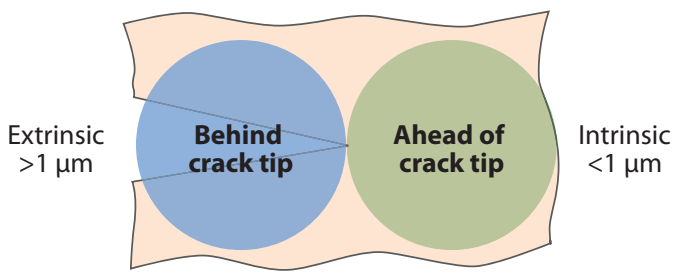

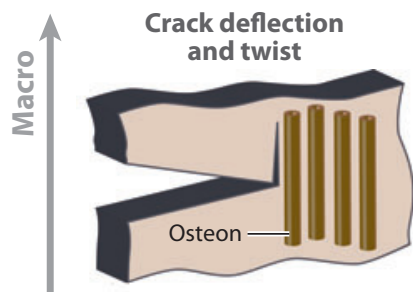

Uncracked-ligament bridging

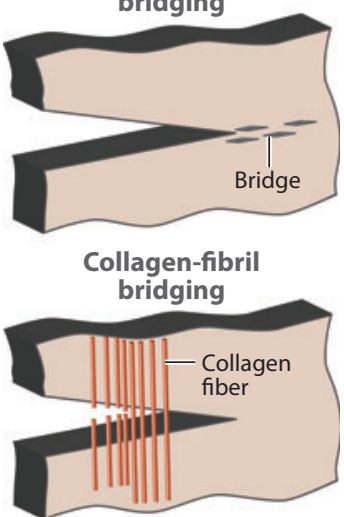

Constrained microcracking

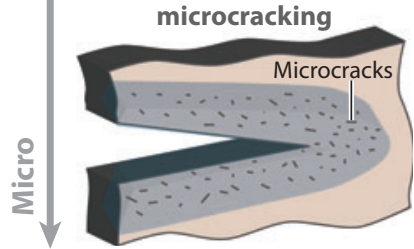

Hidden length (sacrificial bonds)

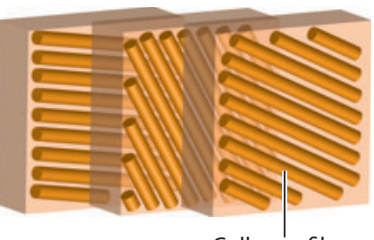

Collagen fiber

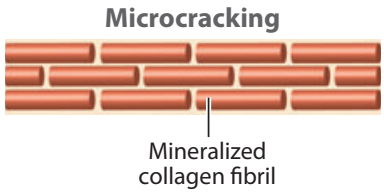

Fibrillar sliding

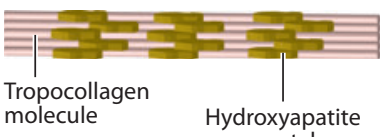

crystal

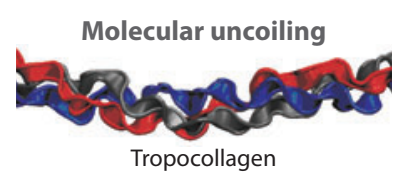

Figure 3

The toughness of bone results from a mutual competition between extrinsic (crack-tip shielding) toughening mechanisms, which predominate at length scales at more than $1 \mu \mathrm{m}$, and intrinsic (plastic deformation) toughening mechanisms, which are active at length scales at primarily less than $1 \mu \mathrm{m}$. Distinct toughening mechanisms occur at each level of hierarchy. Molecular uncoiling and intermolecular sliding of molecules are observed at the smallest level of tropocollagen molecules and mineralized collagen fibrils. Microcracking and fibrillar sliding are observed at the level of fibril arrays. At larger levels, the breaking of sacrificial bonds contributes to increasing the energy dissipation capacity of bone at the interface of fibril arrays, together with crack bridging by collagen fibrils. At the largest length scales in the $10-100-\mu \mathrm{m}$ range, the primary sources of toughening are extrinsic and result from extensive crack deflection and crack bridging by uncracked ligaments, both mechanisms that are motivated by the occurrence of microcracking. 

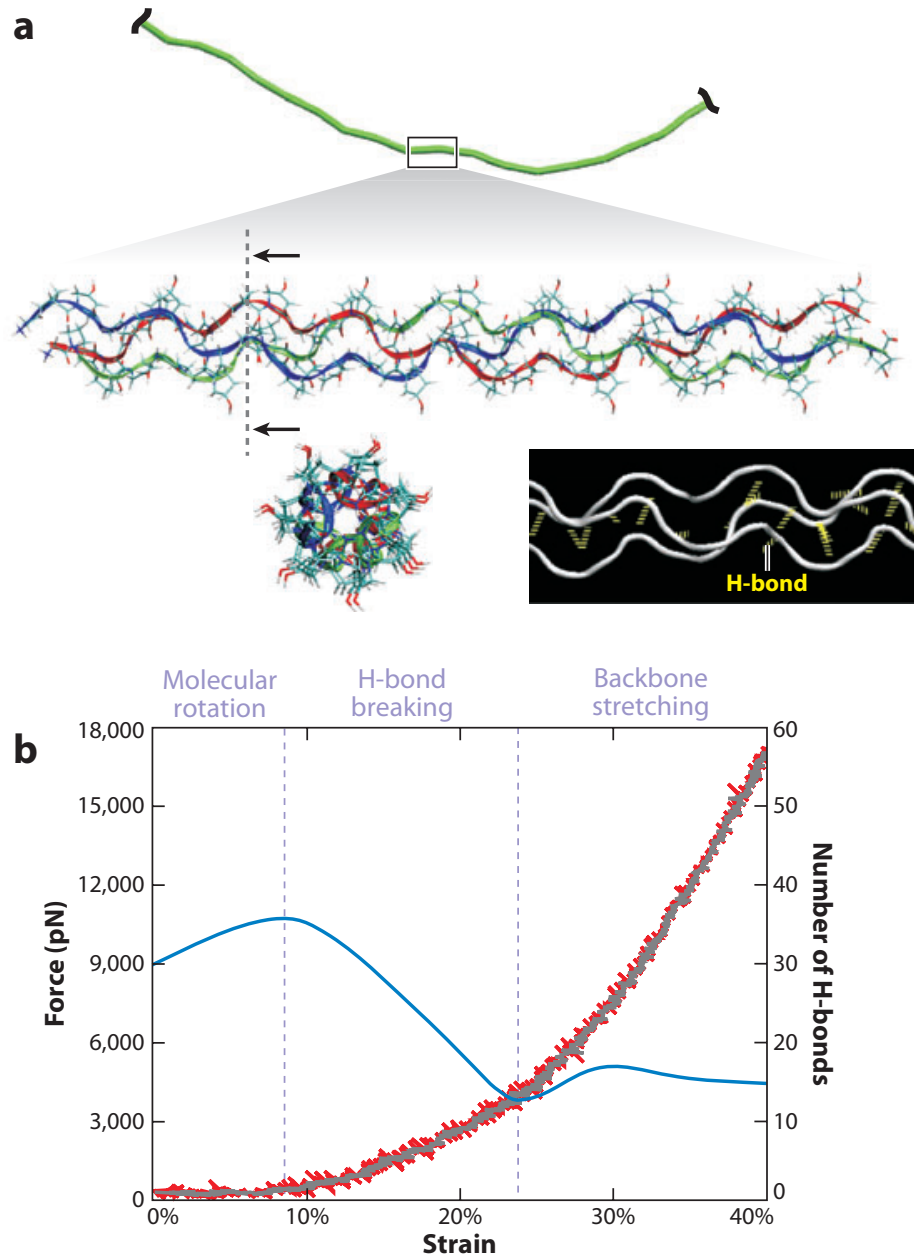

Figure 4

Structure and nanomechanics of a triple-helical tropocollagen molecule, the basic protein building block of bone $(65,67)$. (a) The structure of this protein molecule. The hydrogen-bond (H-bond) structure (yellow, thick, dashed lines) is depicted at the bottom right. (b) The force-extension behavior, here shown up to $40 \%$ strain. Panel $b$ also shows the number of $\mathrm{H}$-bonds (for a tropocollagen segment that is 30 amino acids long). During the first stage of deformation (less than $10 \%$ strain), the number of H-bonds remains close to 30 , corresponding to approximately one H-bond for each amino acid triplet. When tropocollagen is straightened, H-bonds gradually break until $25 \%$ tensile strain is reached. At this point, a stationary situation is attained, with the number of intramolecular H-bonds close to 15 . Beyond this point, the force increase is due to backbone stretching, and no additional H-bonds break. In this regime, no pattern for the remaining $\mathrm{H}$-bonds can be recognized; H-bonds are continuously broken and reformed along the peptide due to the fact that, even if the triple-helical coiling is lost, the three chains are near enough to form H-bonds.

\subsection{Fibrillar Sliding of Mineralized Collagen Fibrils}

The mineralized collagen fibrils are of particular significance for bone, as they are its nanostructural building blocks. Because the mineral phase has an elastic modulus that is more than an order of magnitude higher than that of collagen, the presence of the hydroxyapatite phase is critical to the stiffness of bone. Indeed, experimental results show a continuous increase in Young's modulus 

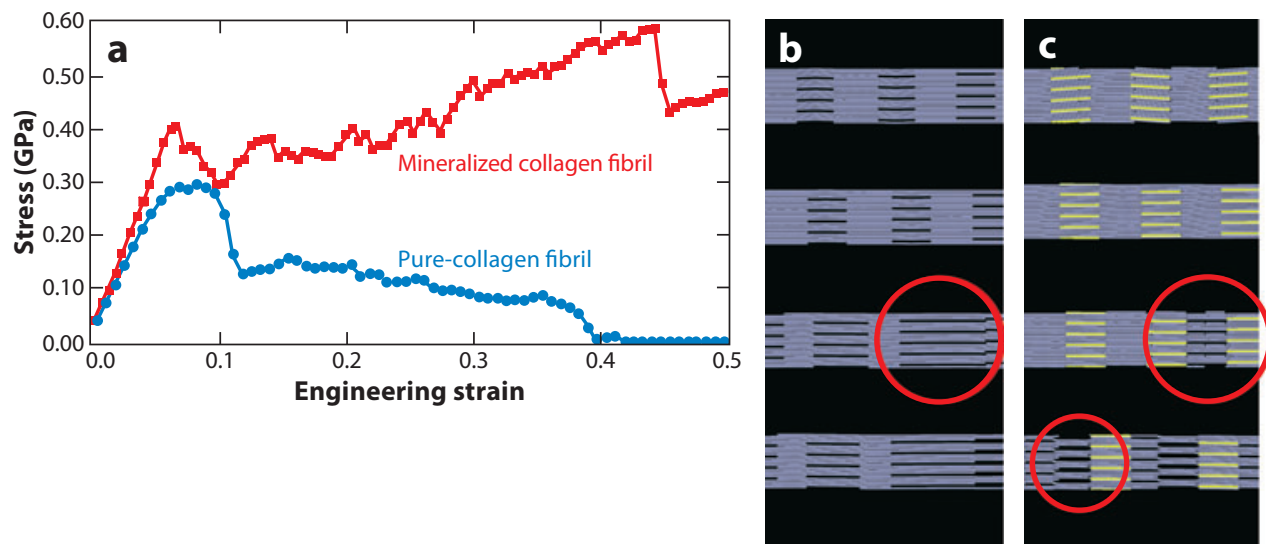

Figure 5

(a) Computational result of the stress-strain response of a mineralized fibril versus an unmineralized collagen fibril, revealing the significant effect that the presence of mineral crystals in collagen fibril has on the mechanical response (66). $(b, c)$ Snapshots of the deformation mechanisms of $(b)$ collagen fibrils and (c) mineral collagen fibrils. Slip initiates at the interface between mineral particles and tropocollagen molecules. Repeated occurrence of slip (red circles denote local areas of repeated molecular slip) reduces the density, leading to the formation of nanoscale voids.

with mineralization of the collagen fibrils, ranging up to a factor of three for high mineral content (16). Molecular modeling and experimental X-ray analysis suggest that continuous glide between tropocollagen molecules and between hydroxyapatite particles and tropocollagen molecules, initiated by slip at the hydroxyapatite/tropocollagen interface, enables a large regime of dissipative deformation once yielding begins, thus effectively increasing the resistance to fracture (66). The larger stresses in the fibrils, preserved due to mineralization, can be maintained after slip initiation because of additional resistance to slip at the interface between the tropocollagen molecules and hydroxyapatite particles; this leads to a several-fold increase in energy dissipation.

Panels $b$ and $c$ of Figure 5 show a nanomechanical analysis of bone deformation, along with structural mechanistic details of the associated deformation mechanisms. This result was obtained by a combination of molecular dynamics simulation and theoretical analysis, which has shown that the characteristic nanostructure of mineralized collagen fibrils is vital for its high strength and its ability to sustain large deformation. Figure $\mathbf{5} \boldsymbol{a}$ shows stress-strain curves under tensile loading for a pure-collagen fibril as compared with those of a mineralized collagen fibril for tensile strains up to $50 \%$. The resulting constitutive behavior is quite different, indicating that precipitation of hydroxyapatite crystals during bone formation significantly alters mechanical behavior. Specifically, the mineralized collagen fibrils display a higher strength and greater energy dissipation under deformation. Plastic deformation starts at $\sim 5 \%$ tissue strain in a pure-collagen fibril and at roughly $30 \%$ higher tensile strains $(\sim 6.7 \%)$ when collagen is mineralized. Furthermore, the mineralized collagen fibrils show higher stiffness and significant softening at larger strains, with a characteristic sawtooth-shaped stress-strain curve due to repeated intermolecular slip. Images of the molecular geometry under increasing tensile load (Figure $\mathbf{5} \boldsymbol{b}, \boldsymbol{c}$ ) imply a deformation mechanism of intermolecular slip that characterizes fibrillar yield. Slip leads to the formation of regions with lower material density, as can be seen in Figure 5.

In addition to providing a mechanism of plastic deformation, such molecular behavior of the protein and mineral phases under large-scale deformation of mineralized collagen fibrils also represents a fibrillar toughening mechanism that leads to an increase of energy dissipation as compared 
with fibrils without a mineral phase $(66,67)$. This is an intrinsic toughening mechanism (Figure 3) that enhances the resistance to fracture by forming larger, local yield regions around crack-like defects, a mechanism that protects the integrity of the entire structure by allowing for localized failure. As a consequence, mineralized collagen fibrils are able to tolerate microcracks on the order of several hundred micrometers in size without causing any macroscopic failure of the tissue.

Specifically, the inclusion of the nanoscale mineral platelets on collagen fibrils increases not only their Young's modulus but also their yield and fracture strengths. In terms of numbers, the Young's modulus, tensile yield strain, and fracture strength for mineralized collagen fibrils are 6.2 GPa, 6.7\%, and 0.6 GPa, respectively, as compared with the corresponding values of $4.6 \mathrm{GPa}$, $5 \%$, and $0.3 \mathrm{GPa}$, respectively, for pure-collagen fibrils.

\subsection{Fibrillar Sliding of Collagen Fiber Arrays}

The long $(>5-10-\mu \mathrm{m})$ and thin $(\sim 100-\mathrm{nm})$ mineralized collagen fibrils are twisted into collagen fibers, which are "glued" together by a thin layer (1-2 nm thick) of extrafibrillar matrix $(68,69)$. When the tissue is externally loaded in tension, the load is resolved into tensile deformation of the mineralized fibrils and shearing deformation in the extrafibrillar matrix (70). Although no precise data on its mechanical behavior or its composition are available, it is likely that the extrafibrillar matrix is composed of noncollagenous proteins, such as osteopontin, and proteoglycans, such as decorin. Indeed, single-molecule spectroscopy of fractured bone surfaces has confirmed that the extrafibrillar matrix has properties similar to those of a glue layer between the fibrils-it is relatively weak but ductile and deforms by the successive breaking of a series of sacrificial bonds $(68,71)$. Specifically, the separation of individual fibrils and the larger fibers during deformation and fracture is resisted by this macromolecular glue via sacrificial bonds that break at a fraction $(\sim 0.1-0.5)$ of the force required to break the backbone of the macromolecules (72). The matrix may also be partially calcified (73), which would increase its shear stiffness and reduce its deformability. These results point toward a deformation mechanism whereby the matrix/fiber interface is disrupted beyond the yield point, and the matrix moves past the fibers forming and reforming the matrix/fiber bonds. An alternative explanation involves the disruption of bonds between the matrix and hydroxyapatite particles and a modification of the frictional stress between individual fibers (74).

\subsection{Microcracking}

At several length scales from the submicrometer scale to a scale of tens of micrometers, the process of microcracking in bone provides the prevalent mechanism of microscale deformation (75-78). As described in the next section, not only is such microcracking a process of plastic deformation, thereby providing an intrinsic contribution to the toughness of bone, but it is an essential phenomenon for the development of the most potent extrinsic toughening mechanisms, notably crack bridging and crack deflection, that predominate at larger length scales (31). Microcracking may also play a crucial role in signaling the remodeling of the bone, which occurs in so-called basic multicellular units (BMUs), i.e., combination of cells that are able to remove (osteoclasts) and form (osteoblasts) bone tissue (21).

\section{EXTRINSIC TOUGHENING (SHIELDING) MECHANISMS}

The (primary) submicrometer deformation mechanisms described above contribute intrinsically to the fracture toughness of bone by forming plastic zones around crack-like defects, thereby protecting the integrity of the entire structure by allowing for localized failure through energy dissipation. However, at micro- to macroscale dimensions, the toughness of cortical bone is associated with a 
very different kind of toughening involving crack-tip shielding (Figure 3). Perhaps surprisingly, the main structural feature that appears to control such extrinsic toughening, namely the osteons, is quite large; osteons are several hundred micrometers in size (79). Akin to many biological materials, these structural features provide a source of toughening that arises during crack growth rather than during crack initiation. To better understand this distinction, it is important to consider that many of the macroscopic fracture toughness properties of bone can be explained mechanistically in terms of the nature of the crack path. A central feature of this fracture behavior is that certain features in the microstructure, especially the interfaces of the osteons, provide microstructurally weak or preferred paths for cracking. As these features have a specific alignment in bone, the osteons provide the basis for the marked anisotropy of the fracture properties of bone (bone is easier to split and to break) $(31,37,80-82)$ and for the fact that the toughness is actually lower in shear than in tension $(80,83,84)$.

\subsection{Constrained Microcracking}

In cortical bone, the path of least microstructural resistance is invariably along the cement lines (80, $83,84)$, which are the hypermineralized interfaces between the bone matrix and secondary osteon structures (e.g., in human bone), or along the similarly hypermineralized boundaries of the primary osteons (e.g., in antler bone). These regions are therefore preferential sites for major microcracks to form, particularly as bone ages and the osteon density increases with remodeling. These microcracks thus have a typical spacing in the tens to hundreds of micrometers and are aligned primarily along the long axis of the bone, an orientation that directly results in the strong anisotropy of toughness in bone. Fracture of hydroxyapatite crystals surrounding collagen fibers or delamination at the crystal/fiber interfaces has been suggested as the cause of such microcracking damage (85).

Because such microcrack formation predominates in the vicinity of a growing (macro) crack where the local stresses are highest, it had been thought that this process was responsible for the marked R-curve toughness behavior in bone (75-78). However, recent calculations $(83,87)$ have clearly shown that, although microcracking is important intrinsically for toughness as a deformation mechanism, its direct extrinsic contribution to toughness is minimal. ${ }^{2}$ However, the importance of microcracking extrinsically is that it results in both crack bridging and crack deflection, which are the most potent toughening mechanisms in bone.

\subsection{Crack Deflection/Twist and Crack Bridging}

The occurrence of microcracking is the source of extrinsic toughening in bone that is associated primarily with mechanisms such as crack deflection/twist and crack bridging (31, 37, 80-82). In fracture, crack trajectories result from the competition between the direction of maximum mechanical driving force [defined by the maximum strain energy release rate, $G_{\max }$, or where the mode II (shear) stress intensity is zero, $K_{\mathrm{II}}=0$ ] and the path of weakest microstructure resistance $(84,88)$. Where these two paths conflict, high toughness generally results. In contrast to the longitudinal orientations, where these preferred mechanical and microstructural crack paths are nominally in the same direction (Figure $\mathbf{6} f, \boldsymbol{j}$ ), these two requirements are incommensurate

\footnotetext{
${ }^{2}$ Such a contribution would arise from the creation of a zone of microcracking surrounding the crack where the stresses are highest. As microcrack formation leads to a dilation in this zone, which is constrained by surrounding regions that are less microcracked, the concept of constrained microcracking involves the advancement of the crack into a zone of compression, thereby inducing extrinsic toughening and R-curve behavior. However, for realistic volume fractions of microcracks in bone, the contribution to the overall toughness from this mechanism has been estimated to be less than $0.1 \mathrm{MPa} \sqrt{\mathrm{m}}(83,87)$.
} 
in the transverse (breaking) orientation: The maximum driving force is oriented parallel to and directly ahead of the crack tip (which promotes coplanar cracking), and the weakest paths are oriented perpendicular to the crack tip along the direction of the major microcracks (Figure $\mathbf{6} \boldsymbol{a}$ $\boldsymbol{e}$ ). In human cortical bone, because the cement lines are oriented nominally along the longitudinal axis of the bone, preferred cracking paths tend to be along this direction. Such orientation can lead to the significant (macroscopic) deflection of cracks that are attempting to propagate in the transverse direction (Figure $\mathbf{6} \boldsymbol{a}, \boldsymbol{e}$ ). This phenomenon makes the transverse orientation so much tougher and makes bone much more difficult to break than to split (80). Recent fracture mechanics measurements show that after only $500 \mu \mathrm{m}$ of cracking, the fracture toughness, specifically the driving force for crack propagation, is more than five times higher in the transverse (breaking) direction than in the longitudinal (splitting) direction (Figure 7) (80).

The major distinction in the toughness between these two orientations in bone can be attributed directly to the marked difference in crack paths (Figure 6), which in turn results in different toughening mechanisms involving primarily crack deflection/twist in the transverse direction and crack bridging in the longitudinal direction.

4.2.1. Crack deflection/twist. In the transverse orientation, the cement line microcracks are aligned roughly perpendicular to the crack path, where they act as delamination barriers. This blunts any growing cracks; causes marked deflections and twists in the crack path (Figure 3); and generates highly tortuous crack paths, extremely rough fracture surfaces, and correspondingly high toughness (Figure $\mathbf{6} \boldsymbol{a}-\boldsymbol{e}$ ). The latter follows because of the reduced local stress field due to crack blunting and the need to reinitiate the crack following local arrest at such delaminations. In addition, such gross crack-path deviations away from the plane of maximum tensile stress greatly diminish the local stress intensity at the crack tip, thereby necessitating higher applied loads to continue cracking (Figure 7) (80, 83).

In addition to its important role in human cortical bone, the process of major crack deflections/twists at the osteon boundaries is also a potent source of toughening in the transverse orientation in other forms of bone, particularly in elk antler bone, which is the toughest biological material on record. Three-dimensional images of crack propagation in antler reveal extensive (out-of-plane) crack twisting at angles of up to $\sim 90^{\circ}$ (Figures $\mathbf{6} \boldsymbol{c}$ and $8 \boldsymbol{a}, \boldsymbol{b}$ ) in addition to in-plane crack deflections (Figure 8a, $\boldsymbol{b}$ ). Linear-elastic calculations using crack-deflection mechanics (89) show that, for in-plane deviations of the crack path, the resulting fracture toughness can be increased by up to a factor of two compared with that of an undeflected crack. Where the crack twists out of plane, this increase can be significantly higher (by a factor of six or more) (90).

4.2.2. Crack bridging. The crack path and consequent salient mechanisms of toughening in the longitudinal orientations are quite different. In human bone, the cement line microcracks are now aligned roughly parallel to the growing crack and thus form ahead of, and parallel to, the main crack tip (termed the "mother and daughter" crack syndrome). The nature of the coalescence of such microcracks to the growing crack leads to the formation of uncracked regions along the crack length (Figures $\mathbf{6} \boldsymbol{b}$ and $\mathbf{8 c}, \boldsymbol{d}$ ) that act to bridge the crack and to carry load that would otherwise be used to further crack propagation $(79,80,83,86,87) .{ }^{3}$ This mechanism of crack bridging, termed uncracked-ligament bridging, also results in toughening but is a far less potent mechanism than that due to crack deflection/twist $(31,80)$.

\footnotetext{
${ }^{3}$ Crack bridging is a common mechanism of extrinsic toughening in many other classes of materials, including the generation of intact fibers spanning crack paths in many fiber-composite materials, the formation of interlocking grain bridges in monolithic ceramics, and ductile-phase bridging in ceramic/metal and ceramic/polymer laminates and composites (29).
} 
Transverse
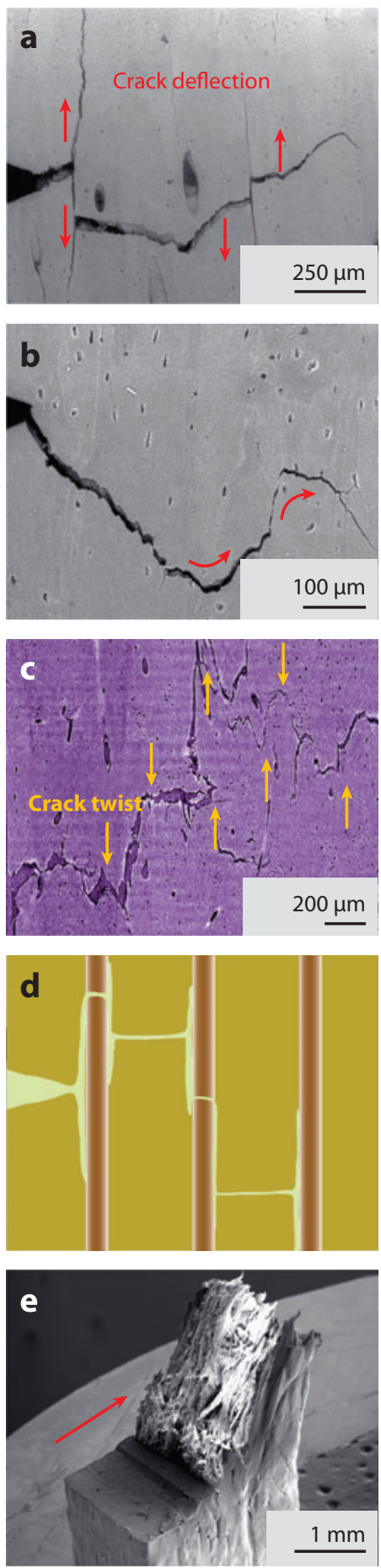

Longitudinal
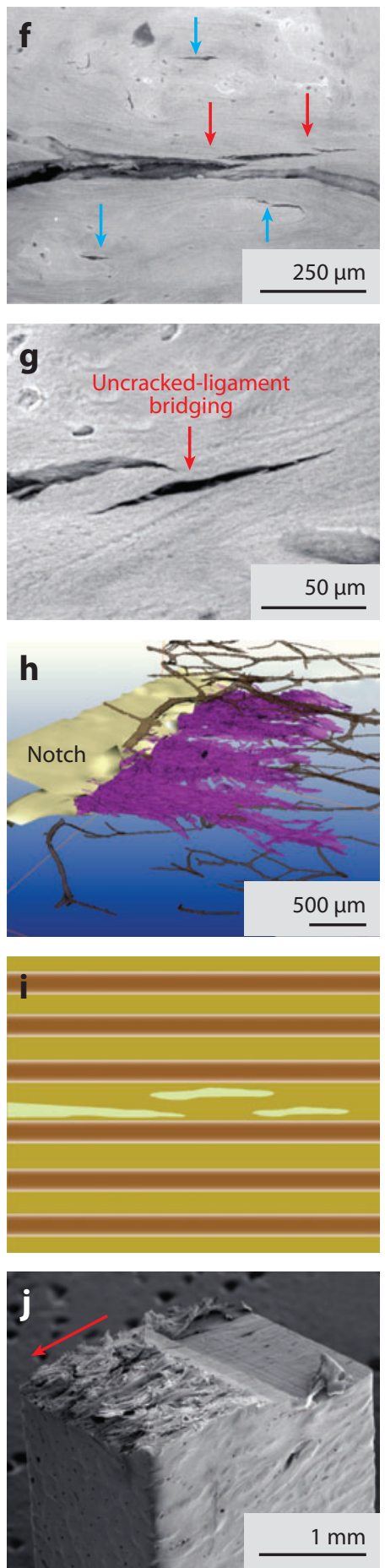
At smaller dimensions, there are other modes of crack bridging in bone. One prevalent form of bridging at micrometer to submicrometer length scales is that due to fibrils that span many of the microcracks that form in bone (Figure 3) (82). Fibril and fiber bridging does not contribute much to the overall toughness $(\sim 0.1 \mathrm{MPa} \sqrt{\mathrm{m}})$ for a single propagating crack $(80,83)$ but is important for its cumulative, integrated effect throughout the numerous microcracks that are generated in bone.

\section{CASE STUDY: TOUGHENING IN ANTLER BONE}

As noted above, one of the toughest materials in nature is the cortical bone in elk antlers. We choose this here as an example of how bone is toughened at multiple length scales by both intrinsic (plasticity) and extrinsic (shielding) mechanisms (91). Elk antler has the highest strain to failure of the entire bone family, with an ultimate tensile strain of $\sim 12 \%$ (Figure 9), which is six times higher than the ultimate tensile strain of the human cortical bone ( 2\%) (16). Evaluation of the R-curve behavior using nonlinear-elastic fracture mechanics (see Appendix) clearly demonstrates that antler bone, like human bone, derives most of its resistance to fracture extrinsically during crack growth. $J$ values reach exceptionally high values of $\sim 60 \mathrm{~kJ} \mathrm{~m}^{-2}$ over the first $600 \mu \mathrm{m}$ of crack extension (Figure 10c,d ), representing the highest toughness for any biological material reported to date (92). This is twice the toughness of human cortical bone (humerus) in the same orientation $\left(J \sim 30 \mathrm{~kJ} \mathrm{~m}^{-2}\right)(80)$. In contrast, antlers tested in their longitudinal orientations (in-plane and antiplane) are not as tough but still reach a (steady-state) fracture toughness of $J_{\mathrm{c}} \sim 4-5 \mathrm{~kJ} \mathrm{~m}^{-2}$, i.e., more than an order of magnitude higher than in human cortical bone (to extend a crack $\sim 500 \mu \mathrm{m}$ ). Analogous to human cortical bone, the extrinsic component to this toughening is associated with extensive crack deflection and twisting in the transverse (breaking) orientation and with uncrackedligament bridging in the longitudinal (splitting) orientation; both processes are motivated by extensive microcracking along the hypermineralized interfaces of the primary osteons (91).

Traditionally, however, the high fracture toughness of antler bone has been attributed to the relatively high organic volume fraction and a higher potency of microcracking $(77,93,94)$. A characteristic of the mechanical properties of antler bone is its lower transverse strength and much lower stiffness compared with human bone, which is associated with its extensive plasticity (Figure 9). This other major contribution to antler bone toughness is now an intrinsic mechanism. The low yield strength in the longitudinal direction allows crack-tip plastic zones

\section{Figure 6}

Mechanisms for stable crack propagation and toughening in the transverse and longitudinal orientations of hydrated cortical bone. Environmental scanning electron microscope (ESEM) backscattered electron images of stable crack growth during in situ R-curve testing in the $(a, b)$ transverse and $(f, g)$ longitudinal orientations. Synchrotron X-ray computed microtomography images of the crack path in both $(c)$ the transverse and (b) the longitudinal orientations of compact bone. $(e, j)$ SEM fractography images and $(d, i)$ schematics of the crack trajectory for each orientation. In the transverse direction $(a-e)$, the prominent toughening mechanisms are in-plane crack deflection and out-of-plane crack twisting. (c) A through-thickness slice from the front face to the back face near the crack tip highlighting the twists of the crack through the sample. The arrows indicate some of the major twists at $\sim 90^{\circ}$. In the longitudinal (splitting) orientation $(b)$, the crack is very planar, with little evidence of deflection. The dominating toughening mechanism here is uncrackedligament bridging $(f, g, h, i)$. The red arrows indicate the direction of deflection (in $a, b)$, the direction of crack propagation (in $e, j$ ), and uncracked-ligament bridges (in $f, g$ ) involving two-dimensional uncracked regions along the crack path that can bridge the crack on opening (126). The blue arrows delineate microcracks that formed at the osteon/matrix interface along the axis of the bone. Such microcracking is essential for many of the toughening mechanisms in bone, notably crack bridging and crack deflection, that predominate at micrometer scales and above. 


$\begin{array}{ll}\text { Transverse } & \text { Longitudinal } \\ \text { Thick plate, HBSS, } 1 \mu \mathrm{m} \mathrm{s}^{-1} & \bigcirc \mathrm{HBSS}, 6 \mu \mathrm{m} \mathrm{s}^{-1} \\ \text { O HBSS, } 6 \mu \mathrm{m} \mathrm{s}^{-1} & \square \mathrm{HBSS}, 0.04 \mu \mathrm{m} \mathrm{s}^{-1} \\ \text { O HBSS, } 1 \mu \mathrm{m} \mathrm{s}^{-1} & \square \text { ESEM, } 0.04 \mu \mathrm{m} \mathrm{s}^{-1} \\ \square \text { ESEM }, 0.04 \mu \mathrm{m} \mathrm{s}^{-1} & \end{array}$
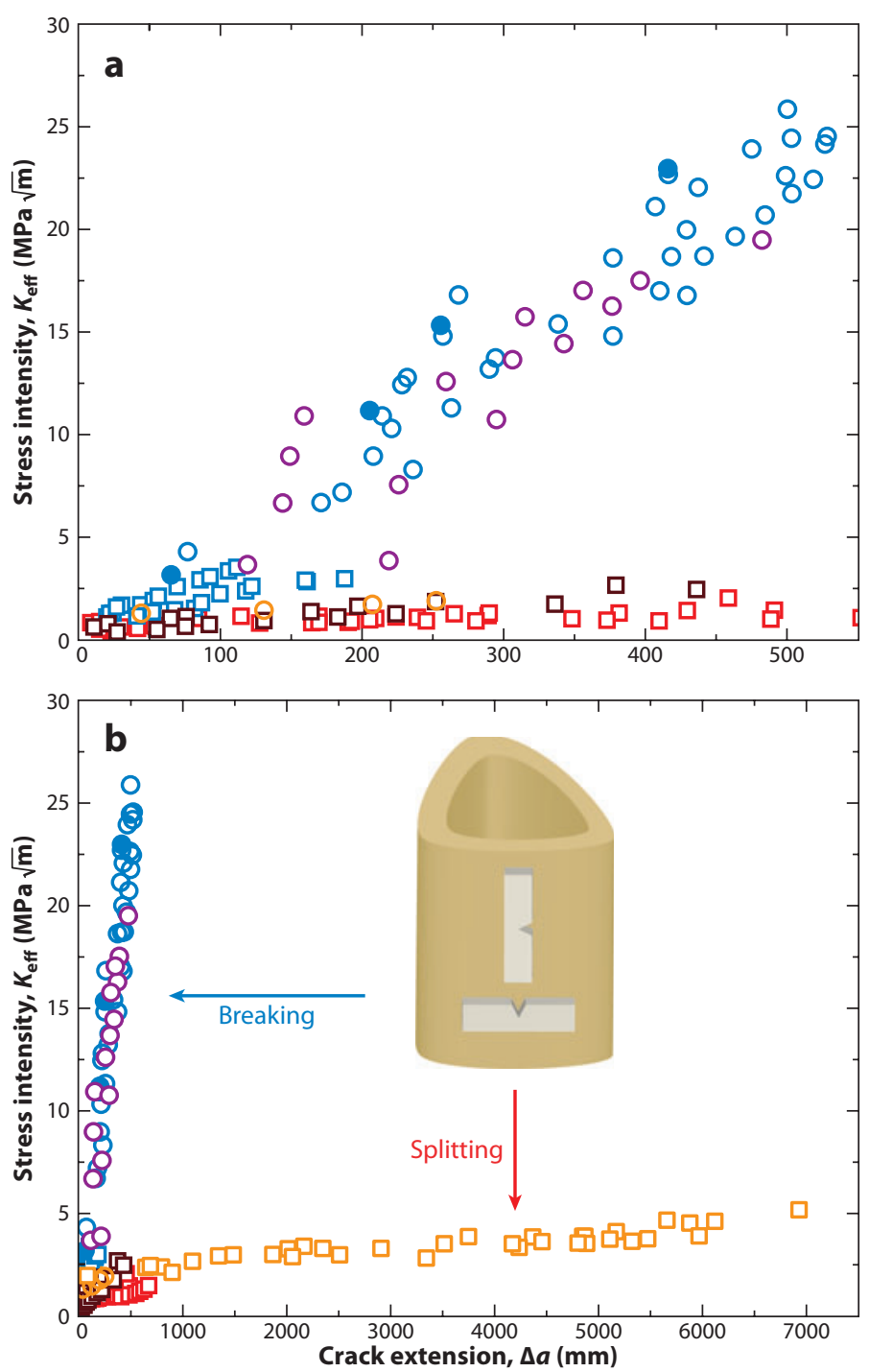

Figure 7

Fracture toughness resistance curve data for the transverse and longitudinal orientations in hydrated human cortical bone. Nonlinear-elastic fracture mechanics measurements of the fracture toughness of bone show that resistance to crack propagation increases much more rapidly in the transverse (breaking) direction than in the longitudinal (splitting) direction, for both $(a)$ realistically small $(<500-\mu \mathrm{m})$ and $(b)$ larger $(<7-\mathrm{mm})$ cracks. This phenomenon results from the different primarily toughening mechanisms at play: crack deflection and twist in the transverse orientation (Figure $\mathbf{6} \boldsymbol{a}-\boldsymbol{c}$ ) and crack bridging in the longitudinal orientation (Figure $\mathbf{6} \boldsymbol{f}, \boldsymbol{b}$ ). This result was independent of loading displacement rate or loss of constraint. In the legend, ESEM denotes tested in situ in the environmental scanning electron microscope, and HBSS denotes testing ex situ immersed in Hanks' Balanced Salt Solution; individual loading displacement rates are also given. The inset shows the orientation of the samples from the humerus. Adapted with permission from Reference 80. 
Transverse orientation
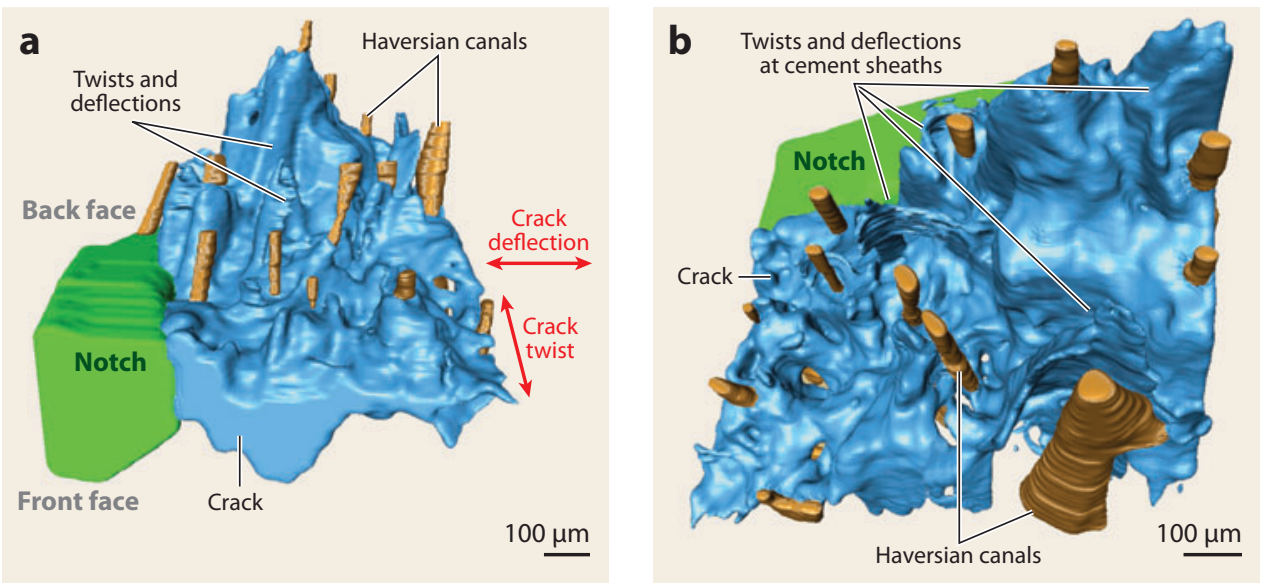

Longitudinal orientation
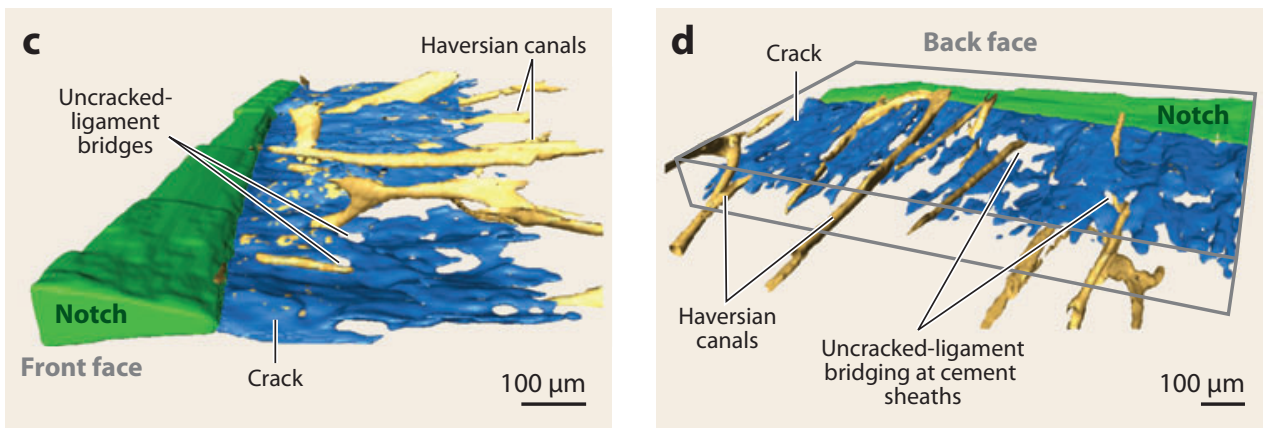

\section{Figure 8}

Three-dimensional reconstructions in the transverse and longitudinal orientations from synchrotron $\mathrm{X}$-ray computed tomography. Panels $a$ and $c$ show an edge on view of the notch and crack to show the shape of the crack paths. Panels $b$ and $d$ are oriented to highlight the dominant toughening mechanisms in the two orientations. The reconstructions show that the principal toughening mechanisms in bone are associated with the cement lines (or sheaths). In the transverse direction, crack twist and deflection dominate the toughness and occur predominantly at the cement sheaths before the crack penetrates the Haversian systems. Three-dimensional imaging in the longitudinal orientation provides novel insight into how the dominant toughening mechanism of uncracked-ligament bridging is associated with Haversian systems. As shown in panel $d$, the crack "flows" around the Haversian system; effectively, the crack does not penetrate the Haversian system but propagates along the surrounding cement sheath, leaving an intact Haversian system bridging the crack faces.

to form at lower stresses than in human bone $(77,93)$, which contributes to the large inelastic deformation and thereby to the intrinsic toughness of antler bone. Such contributions from nanoscale plasticity within the mineralized collagen fibrils are important, although little is known about these mechanisms in antler. Recently, in situ tensile testing on compact antler bone combined with small-angle X-ray diffraction measurements (95) has revealed that, although both antler bone and (bovine) bone show similar nanoscale fibril shearing mechanisms (96) during elastic deformation, with inelastic deformation, i.e., after macroscopic yielding, the mechanisms are different, with inhomogeneous fibril stretching in antler leading to defects and to consequent debonding between neighboring fibrils. The result is that strain localization in antler bone is 


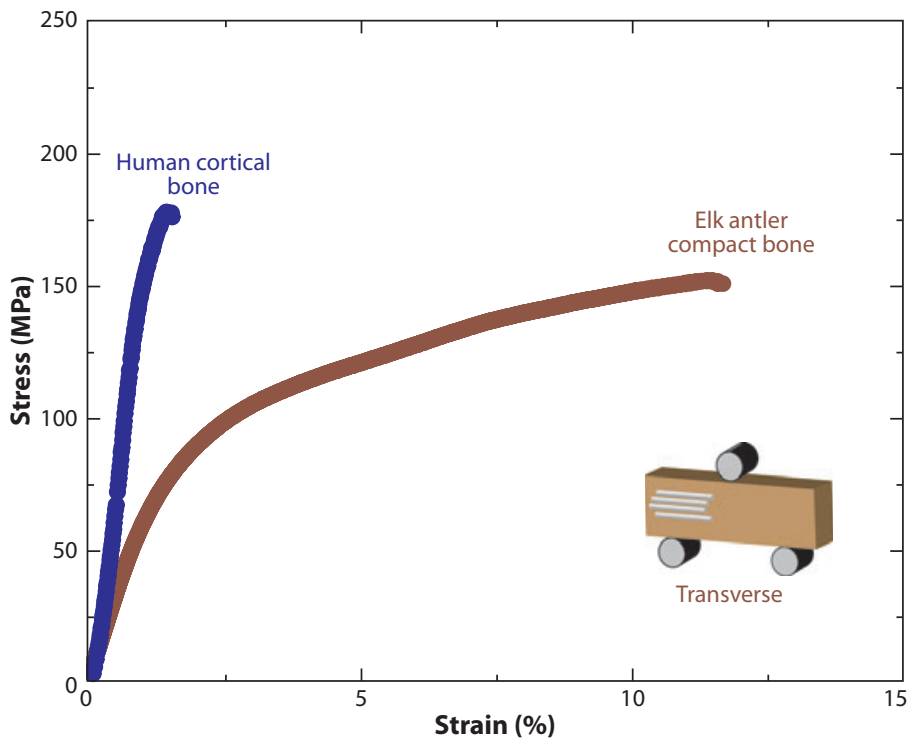

Figure 9

Stress-strain curves from three-point bending tests for hydrated human cortical bone and elk antler in the transverse orientation. Data for elk antler are taken from Reference 120. Adapted with permission from Reference 91.

suppressed at the microscale; moreover, this process is thought to cause the formation of nanoand microcracks, which further contributes to extensive inelastic deformation prior to failure.

The observed characteristic length scales at each hierarchical level in bone are a result of structural adaptation toward maximizing target materials properties such as strength and toughness. As such, compared with human bone, for example, antler is tougher yet is not as strong, highlighting the vital distinction between strength and toughness in biological materials (97). In general, this combination of the intrinsic toughening contributions from (primarily submicrometer) plasticity mechanisms and the potent extrinsic toughening contributions from crack deflection/twist and crack bridging mechanisms (primarily at micrometer dimensions and above) provides the basic description of how bone derives its resistance to fracture.

\section{GENETIC DISEASES IN BONE}

Even though the mineral phase is crucial for creating stiffness and toughness of bone tissue, the collagenous protein phase plays an elementary role in defining the physiological properties of the material. This is evident from the fact that structural alterations, or mutations in the collagen gene, can lead to severe diseases that are associated with a severe deterioration of the mechanical properties of bone. Notably, these mutations can be minute and encompass only one out of thousands of amino acids yet have catastrophic effects on the performance of collagenous tissues and bone in the physiological setting.

One of the best-known genetic diseases is osteogenesis imperfecta, or brittle-bone disease, in which tiny single-point mutations (i.e., molecular defects at the level of single amino acids, or a few angstroms in length scale) in the collagen type I gene leads to catastrophic effects at larger scales (98). Experimental analysis of the mechanical properties revealed that the stiffness and strength of osteogenesis imperfecta tissue show mechanical weakness (99). 

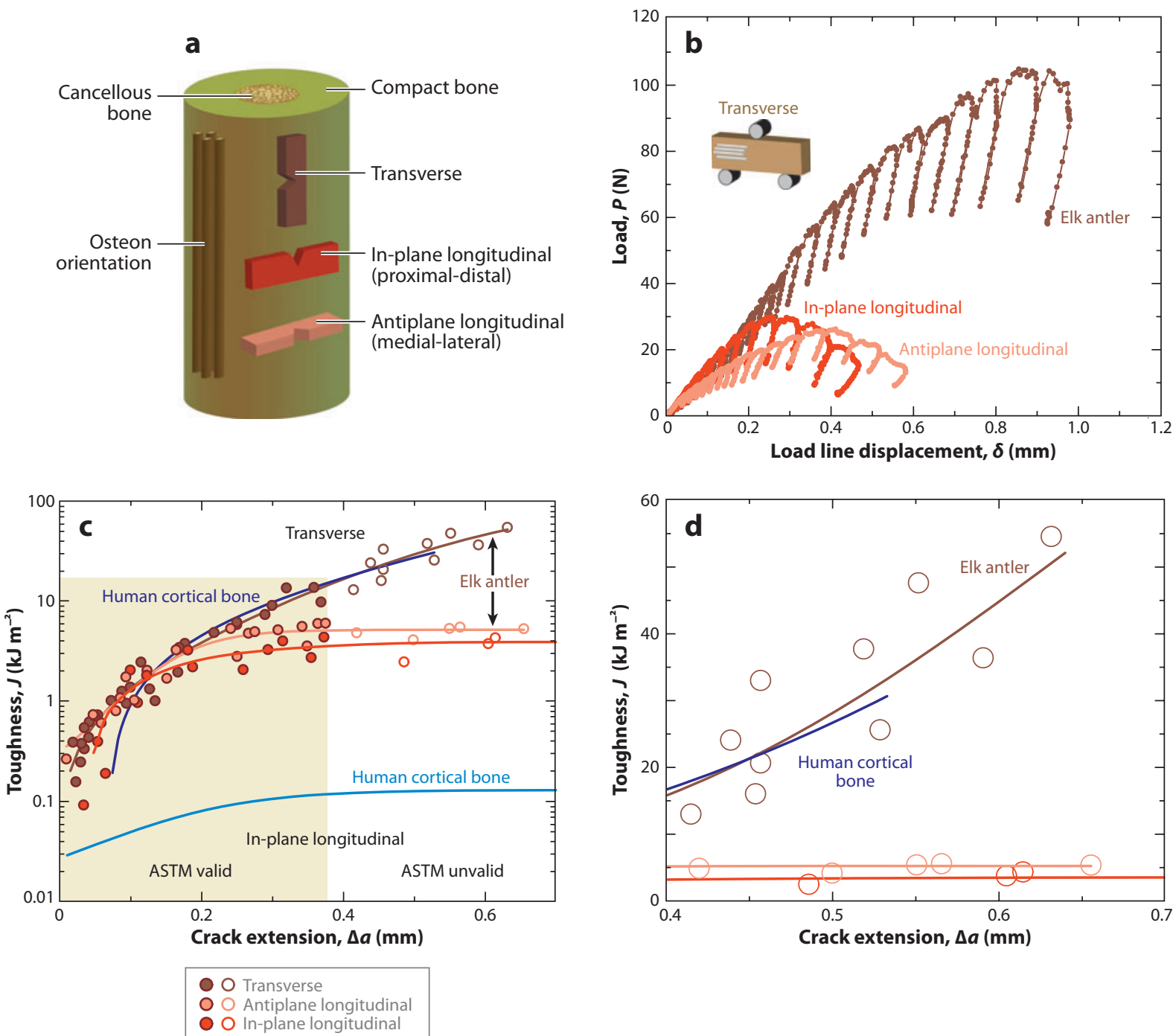

Figure 10

(a) The structure of antler bone, as well as the three anatomical orientations of the specimens taken from the compact bone. (b) Curve for typical load versus load line displacement obtained during R-curve testing for the transverse, in-plane longitudinal, and antiplane longitudinal orientations of hydrated antler compact bone. Each partial unloading event during the test corresponds to a data point in panel $c$. (c) Full $J_{\mathrm{R}}(\Delta a)$ resistance curves for stable ex situ crack extension in hydrated antler compact bone tested in the transverse, in-plane longitudinal, and antiplane longitudinal orientations. (d) Expansion of panel $c$ showing $J_{\mathrm{R}}(\Delta a)$ resistance curves at larger crack extension $(\Delta a>400 \mu \mathrm{m})$. The R-curves for short crack lengths $(\Delta a \approx 600 \mu \mathrm{m})$ are compared with data taken from human cortical bone in both the transverse and the in-plane longitudinal orientations of the humerus. Data for elk antler are from Reference 91, and data for human cortical bone are from Reference 80. In the transverse orientation, fracture toughnesses, $J$, of antler compact bone were recorded at nearly $\sim 60 \mathrm{~kJ} \mathrm{~m}^{-2}$, almost two times higher than the critical toughness value, $J_{\mathrm{c}}$, of human cortical bone $\left(J_{\mathrm{c}} \approx 30 \mathrm{~kJ} \mathrm{~m}^{-2}\right)$. The validity of these data points is defined by the measurement capacity of each specimen in accordance with the ASTM standard (121). The circles in panels $c$ and $d$ correspond to data points for antler bone. Adapted with permission from Reference 91. 
Materials science can be a useful tool to improve our understanding of such genetic diseases and, in particular, bring about the role of materials in the initiation and progression of disease states. Materiomics is the study of the material properties of natural and synthetic materials by examining fundamental links between processes, structures, and properties at multiple scales, from nano to macro, through the use of systematic experimental, theoretical, or computational methods. Materiomics is a powerful approach in examining the role of material breakdown in the context of disease (67). The term materiomics was coined in analogy to genomics, the study of an organism's entire genome. Similarly, materiomics refers to the study of the entirety of processes, structures, and properties of materials from a fundamental, systematic perspective by incorporating all relevant length scales in the synthesis and function of materials and structures. The integrated view of these interactions at all scales is referred to as a material's materiome. Recent materiomics studies carried out using a hierarchy of atomistic and molecular multiscale simulation techniques elucidated the molecular and mesoscale mechanism of osteogenesis imperfecta, or brittle-bone disease. These studies also showed that the mutation leads to the formation of tiny cracks at the molecular scale due to a softening of the tropocollagen molecule's stiffness and a significant reduction of the intermolecular adhesion, effectively resembling the formation of nanocracks (100, 101) (see Figure 11).

The presence of these nanocracks results in a change in the fibril's stress distribution, leading to locally large shear stresses that induce the propensity of material failure due to intermolecular shear. This example shows that under disease conditions, the intrinsic repair and toughening mechanisms of bone can fail to function properly and can lead to a rapid breakdown of the tissue (4). Other collagen gene-related diseases include some forms of dwarfism, Alport's syndrome, and Ehlers-Danlos syndrome (56, 102-104).

\section{DEGRADATION WITH AGING}

Despite the development of such fracture resistance in human bone, the risk of bone fracture increases markedly with aging. As noted above, this increase in risk has been traditionally related to a loss in bone mass (osteoporosis), but we now realize that there is an additional degradation in the quality of bone with age. Fracture toughness measurements on 34-99-year-old human cortical bone show some $40 \%$ reduction in the crack-initiation toughness and almost complete elimination of the crack-growth toughness with increasing age (Figure 12) (86). The reasons for this are complex and not totally clear $(79,86)$. With aging, at the nanoscale there are distinct changes in the collagen environment specifically with regard to an increased degree of cross-linking: At the submicrometer scale, the nature and properties of individual collagen fibrils deteriorate, and at the scale of $1 \mu \mathrm{m}$ to $100 \mu \mathrm{m}$, the microstructure at the bone level changes due to an increased density of osteons, the latter having perhaps the largest effect on the macroscale fracture toughness properties (79). With progressive aging, human bone is remodeled at the interior of the cortex (Haversian remodeling), which then stimulates further remodeling as the growing cement lines sever the tiny canals that connect interstitial bone cells, leading to cell death (16). As a result, the density of osteons increases with age (79). Because the cement lines provide the prime sites for microcrack formation, the increased osteon density gives rise to $(a)$ a higher microcrack density, which can be associated with a diminished crack-initiation toughness, and more importantly to (b) smaller uncracked-ligament bridges spanning the crack, which in turn significantly degrade the crack-growth toughness. Such age-induced degradation in the potency of crack bridging in bone has been directly measured and is a major reason for the severe reduction in fracture resistance of bone with aging $(31,79)$. 

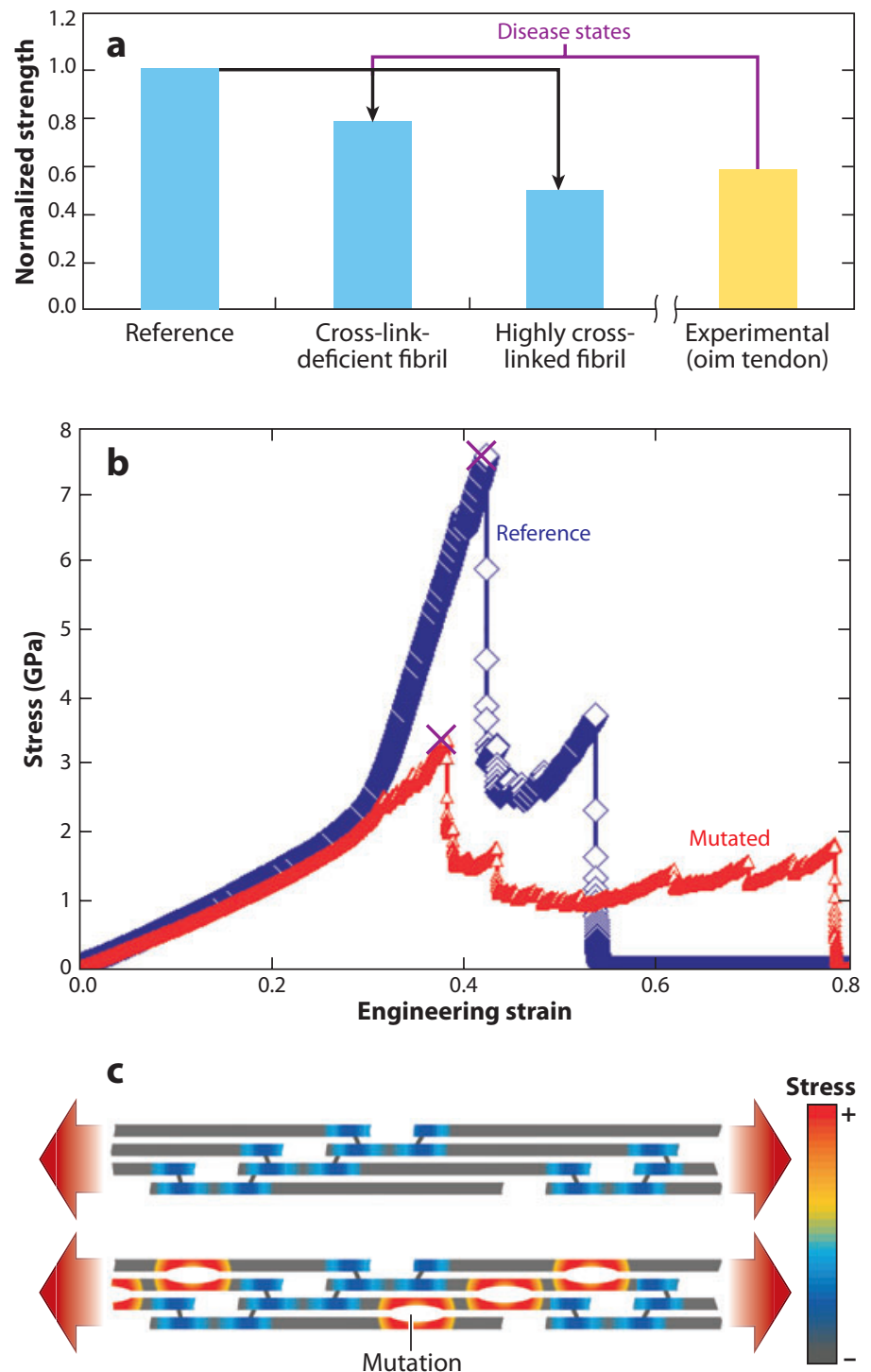

Figure 11

Effects of osteogenesis imperfecta mutations on mechanical properties of collagenous tissues, based on computational multiscale $(100,101)$ and experimental (99) results. Panel $a$ shows the effect of the mutations on the strength properties of collagen fibrils and tendon. Panel $b$ shows two stress-strain curves representing the reference case without mutations and the mutated sample. A severe change in the stress-strain response can be observed. Panel $c$ schematically highlights the effect of the mutations on the internal stress distribution, where the formation of nanocracks leads to large shear stresses inside the fibril.

\section{CLOSING REMARKS}

Because bone is such a complex biological material, we still possess only a limited quantitative understanding of how it deforms and fractures or of the salient plasticity and toughening mechanisms active at the various structural length scales and timescales. The advent of multiscale observations, high-resolution structural imaging using transmission electron microscopy and computed X-ray 


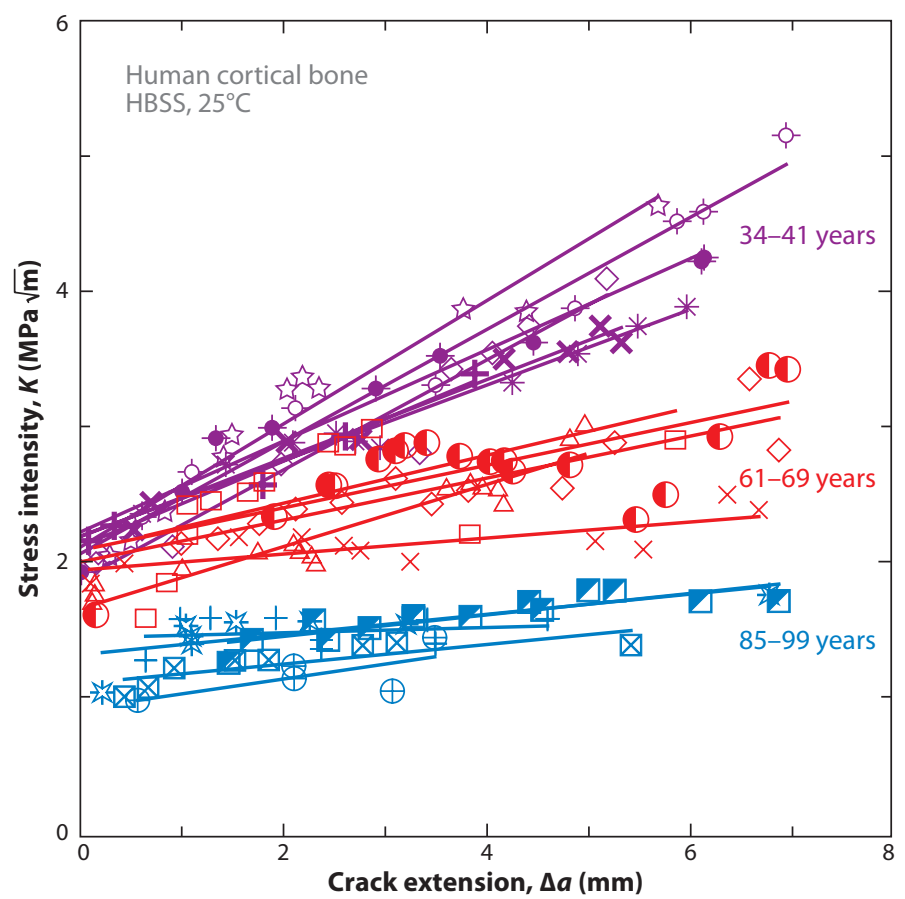

Figure 12

Crack-resistance curves (R-curves) for stable ex vivo crack extension in human cortical bone as a function of age from 34-41 years to 85-99 years, tested in Hanks' Balanced Salt Solution (HBSS) at $25^{\circ} \mathrm{C}$. The crack-initiation toughness, $K_{0}$, is represented by the intercept of the R-curve on the stress intensity axis at $\Delta a \rightarrow 0$. The crack-growth toughness is given by the slope of the R-curve. Although the crack-initiation toughness is decreased by roughly a factor of two with aging, the decrease in crack-growth toughness with aging is far greater-by roughly a factor of ten. Adapted with permission from Reference 86.

microtomography, and vastly more powerful theoretical and computational tools, however, now enables the analysis of bone as a material with rigorous physical science techniques. These types of studies that seek to uncover, model, and quantify the fundamental nano- to macroscale mechanisms that govern the properties of bone are quite distinct from those that have been traditionally used in the bone and medical communities. From the current work, we can conclude that origins of fracture resistance in bone can be traced to a suite of mechanisms acting at numerous length scales, from nano to macro. These mechanisms can be classified as (a) plasticity mechanisms that operate principally at submicrometer dimensions to promote intrinsic toughness and that involve molecular uncoiling of collagen molecules, fibrillar sliding of mineralized collagen fibrils and individual collagen fibers, and microcracking and $(b)$ crack-tip shielding mechanisms that operate at length scales of $\sim 1 \mu \mathrm{m}$ to $100 \mu \mathrm{m}$ to promote extrinsic (crack-growth) toughness via such mechanisms as crack deflection/twist and crack bridging. In contrast, certain molecular-level alterations in the structure of constituting collagen molecules due to genetic mutations can result in a catastrophic breakdown of bone tissue, indicating a lack of an ability of bone to deal with certain structural changes. We believe that the results from such materials science-based studies, although not mainstream medical science, can positively impact the medical field by providing new and different insights into bone-related diseases, aging, and the remodeling properties of bone and, as such, help in the search for new cures and treatment options for a variety of bone diseases. 


\section{DISCLOSURE STATEMENT}

The authors are not aware of any affiliations, memberships, funding, or financial holdings that might be perceived as affecting the objectivity of this review.

\section{ACKNOWLEDGMENTS}

This work was supported by the Laboratory Directed Research and Development Program of Lawrence Berkeley National Laboratory (LBNL) and by the Office of Science, Office of Basic Energy Sciences, Division of Materials Sciences and Engineering of the U.S. Department of Energy under contract number DE-AC02-05CH11231. The use of the X-ray synchrotron microtomography beam line (8.3.2) at the Advanced Light Source at LBNL, supported by the Office of Science of the U.S. Department of Energy, is also acknowledged. M.J.B. acknowledges support from the Army Research Office (contract number W911NF-06-1-0291) and support from a National Science Foundation CAREER award (contract number 0642545). The authors would like to thank many individuals who have been engaged in various parts of this work, including Joel Ager, Sabine Bechtle, Tony Keaveny, John Kinney, Kurt Koester, Jay Kruzic, Joanna McKittrick, Ravi Nalla, Eduardo Saiz, and Tony Tomsia.

\section{APPENDIX: QUANTITATIVE ASSESSMENT OF TOUGHNESS IN BONE}

As described above, significant efforts have been made over the past ten years or so to elucidate how bone is toughened. One important aspect of such efforts is how to quantitatively measure the macroscopic toughness of bone. Traditionally, this has been achieved by measurements of the work of fracture, $W_{\mathrm{f}}$, which is obtained by dividing the area under the load-displacement curve measured during the toughness test by twice the nominal crack-surface area. This approach has been widely used in the past to quantify the toughness of cortical bone in unnotched (nominally flaw-free) specimens $(16,17,105-110)$ but suffers from the fact that the results can be dependent on both specimen size and geometry. Consequently, work-of-fracture measurements are generally not too useful for comparing toughness values determined in different studies that utilized different sample geometries, but they may be used successfully to assess trends when the nominal sample size and geometry are held constant.

The fracture of bone, akin to that of other structural materials, is best characterized using fracture mechanics methods. In its simplest form, this involves linear-elastic fracture mechanics (LEFM) assessments of toughness, which have been widely used for bone. Here we must make an assumption that bone is a linear-elastic material, specifically that any inelastic (e.g., yielding) behavior is limited to a small near-tip region such that the stress and displacement fields local to the tip of a preexisting crack can be described by the stress-intensity factor, $K$, where $K$ can be defined for mode I (tensile-opening loading), for mode II (shear loading), or for mode III (tearing or antishear loading) $(97,111)$. There is a large body of results in the literature involving assessments of the fracture toughness of cortical bone using LEFM. Such works have involved single-parameter characterization of the toughness using either the critical value of the mode I linear-elastic stress intensity, $K_{I c}(110,112-115)$, or the related strain-energy release rate, $G_{c}(116,117){ }^{4}$

\footnotetext{
${ }^{4}$ The fracture toughness, $K_{i c}$ (where $i=\mathrm{I}, \mathrm{II}$, or III), is the critical value of the stress intensity $K$ for unstable fracture in the presence of a preexisting crack, e.g., in mode I when $K_{I}=Y \sigma_{\text {app }}(\pi a)^{1 / 2}=K_{I c}$, where $\sigma_{\text {app }}$ is the applied stress, $a$ is the crack length, and $Y$ is a function (of order unity) of crack size and geometry. The alternative LEFM approach is to express the toughness as a critical value of the strain-energy release rate, $G_{c}$, defined as the change in potential energy per unit increase in
} 
Whereas such a fracture mechanics approach represents a significant improvement over measurements of toughness involving parameters such as the work of fracture, single-value linearelastic fracture parameters based on crack initiation, such as $K_{I c}$, cannot capture, or even represent, the multiple length-scale toughening acting in cortical bone. As described in this article, although intrinsic (deformation) mechanisms govern primarily the crack-initiation toughness, the predominant toughening mechanisms in bone are extrinsic and hence operate largely in the wake of the crack to govern the crack-growth toughness. This results in some degree of stable cracking before unstable fracture, leading to characteristic resistance-curve (R-curve) behavior (76, 77, 86, $94,118,119)$, where the fracture resistance actually increases with crack extension. ${ }^{5}$

Although such linear-elastic stress-intensity-based R-curves do provide a means to characterize crack propagation, the underlying assumptions for such $K_{\mathrm{R}}$ calculations do not account for the energy associated with plastic deformation during bone fracture, which is associated with intrinsic toughening in bone. The LEFM approach is valid only where small-scale yielding conditions apply (111), i.e., where the extent of local (crack-tip) inelasticity is small compared with the size of the bone or test sample. This places restrictions on how large a test specimen has to be for valid toughness measurements; namely, the in-plane specimen dimensions of crack size and the width of the remaining uncracked ligament must be at least an order of magnitude larger than the plasticzone size (small-scale yielding). Additionally, for geometry- and thickness-independent toughness values, the out-of-plane thickness dimension must be equally larger than the plastic zone (plane strain conditions). For example, in antler bone, a LEFM $K_{I c}$ value of $\sim 10 \mathrm{MPa} \sqrt{\mathrm{m}}$ (120) would require test specimen dimensions (in terms of crack size, ligament depth, and thickness) in excess of $50 \mathrm{~mm}$ for a valid linear-elastic $K_{I c}$ based on current ASTM validity criteria (121). Because the thickness of the cortical shell in antler bone is typically only $\sim 5 \mathrm{~mm}$, LEFM $K_{I c}$ measurements are not an appropriate means to measure its toughness; the distribution in local stresses and displacements near a crack tip (i.e., near the fracture origin) would not be represented by the $K$-field (122) such that the resulting $K$-based toughness values would be highly questionable. This may not be the situation for all bones, but in the majority of cases, the bone size in comparison to the extent of local plasticity will be insufficient for LEFM toughness measurements to be reliable (or independent of geometry and size).

Accordingly, to assess the toughness of bone material, with its large postyield deformation and subcritical cracking behavior, an R-curve approach based on a nonlinear-elastic fracture mechanics approach is essential to provide a more realistic description of the crack-tip stress and displacement fields and furthermore is able to capture the contribution to the toughness from the energy consumed in plastic deformation prior to and during fracture $(80,123)$. The best approach here appears to be the use of the $J$-integral as the crack-driving force, where $J$ is the nonlinear strainenergy release rate, i.e., the rate of change in potential energy for a unit increase in crack area in a nonlinear-elastic solid (the nonlinear-elastic equivalent of $G$ ). In analogous fashion to $K$ in linear-elastic materials, $J$ characterizes the stress and displacement fields at a crack tip in a nonlinear-elastic solid and as such can be used to define the onset of fracture in such a material. Descriptions of the use of $J$-integral measurements for bone can be found in References 80, 81, 91 , and 123 . Indeed, $J$-integral measurements have now been used to quantify the toughness of

\footnotetext{
crack area. The relationship between these two parameters is given by $G=\frac{K_{I}^{2}}{E}+\frac{K_{I I}^{2}}{E}+\frac{K_{I I}^{2}}{2 \mu}$, where $E$ and $\mu$ are the Young's modulus and shear modulus, respectively.

${ }^{5}$ The R-curve provides an assessment of the fracture toughness in the presence of subcritical crack growth. It involves measurements of the crack-driving force, e.g., $K$ or $J$, as a function of crack extension $(\Delta a)$. The value of the driving force at $\Delta a \rightarrow 0$ provides a measure of the crack-initiation toughness, whereas the slope (or maximum value) of the $\mathrm{R}$-curve can be used to characterize the crack-growth toughness.
} 
several biological materials, including bone (80, 81, 91, 123), dentin (124), and nacre (125). In this work, the majority of fracture toughness and R-curve measurements shown were performed using nonlinear-elastic fracture mechanics, although for clarity, back-calculated $\mathrm{K}$ values are presented.

\section{LITERATURE CITED}

1. Aizenberg J, Weaver JC, Thanawala MS, Sundar VC, Morse DE, Fratzl P. 2005. Skeleton of Euplectella sp.: structural hierarchy from the nanoscale to the macroscale. Science 309:275-78

2. Fratzl P, Weinkamer R. 2007. Nature's hierarchical materials. Prog. Mater. Sci. 52:1263-334

3. Espinosa HD, Rim JE, Barthelat F, Buehler MJ. 2009. Merger of structure and material in nacre and bone: perspectives on de novo biomimetic materials. Prog. Mater. Sci. 54:1059-100

4. Buehler MJ, Yung YC. 2009. Deformation and failure of protein materials in physiologically extreme conditions and disease. Nat. Mater. 8:175-88

5. Aizenberg J, Fratzl P. 2009. Biological and biomimetic materials. Adv. Mater. 21:387-88

6. Ortiz C, Boyce MC. 2008. Materials science: bioinspired structural materials. Science 319:1053-54

7. Mayer G. 2005. Rigid biological systems as models for synthetic composites. Science 310:1144-47

8. Currey JD. 2005. Materials science: hierarchies in biomineral structures. Science 309:253-54

9. Lakes R. 1993. Materials with structural hierarchy. Nature 361:511-15

10. Jeronimidis G, Atkins AG. 1995. Mechanics of biological materials and structures: nature's lessons for the engineer. Proc. Inst. Mech. Eng. C 209:221-35

11. Ackbarow T, Sen D, Thaulow C, Buehler MJ. 2009. Alpha-helical protein networks are self-protective and flaw-tolerant. PLoS ONE 4:e6015

12. Qin Z, Kreplak L, Buehler MJ. 2009. Hierarchical structure controls nanomechanical properties of vimentin intermediate filaments. PLoS ONE 4:e7294

13. Jeronimidis G. 2000. Structure-property relationships in biological materials. In Structural Biological Materials, Design and Structure-Property Relationships, ed. M Elices, pp. 3-29. Amsterdam: Pergamon

14. Fratzl P. 2007. Biomimetic materials research: What can we really learn from nature's structural materials? 7. R. Soc. Interface 4:637-42

15. Meyers MA, Chen PY, Lin AYM, Seki Y. 2008. Biological materials: structure and mechanical properties. Prog. Mater. Sci. 53:1-206

16. Currey JD. 2002. Bones. Princeton: Princeton Univ. Press

17. Currey JD. 1979. Mechanical properties of bone tissues with greatly different functions. F. Biomech. 12:313-19

18. Currey JD. 1999. The design of mineralised hard tissues for their mechanical functions. F. Exp. Biol. 202:3285-94

19. Martin RB, Burr DB. 1989. Structure, Function, and Adaptation of Compact Bone. New York: Raven

20. Taylor D. 2003. Failure processes in hard and soft tissues. In Comprehensive Structural Integrity: Fracture of Materials from Nano to Macro, ed. I Milne, RO Ritchie, BL Karihaloo, pp. 35-95. Oxford, UK: Elsevier

21. Taylor D, Hazenberg JG, Lee TC. 2007. Living with cracks: damage and repair in human bone. Nat. Mater. 6:263-68

22. Hui SL, Slemenda CW, Johnston CC. 1988. Age and bone mass as predictors of fracture in a prospective study. F. Clin. Investig. 81:1804-9

23. Kiebzak GM. 1991. Age-related bone changes. Exp. Gerontol. 26:171-87

24. Heaney RP. 2003. Is the paradigm shifting? Bone 33:457-65

25. Rho JY, Kuhn-Spearing L, Zioupos P. 1998. Mechanical properties and the hierarchical structure of bone. Med. Eng. Phys. 20:92-102

26. Weiner S, Wagner HD. 1998. The material bone: structure mechanical function relations. Annu. Rev. Mater. Sci. 28:271-98

27. Ritchie RO. 1988. Mechanisms of fatigue crack-propagation in metals, ceramics and composites: role of crack tip shielding. Mater. Sci. Eng. A 103:15-28

28. Launey ME, Ritchie RO. 2009. On the fracture toughness of advanced materials. Adv. Mater. 21:2103-10 
29. Ritchie RO. 1999. Mechanisms of fatigue-crack propagation in ductile and brittle solids. Int. 7. Fract. 100:55-83

30. Evans AG. 1990. Perspective on the development of high-toughness ceramics. F. Am. Ceram. Soc. 73:187206

31. Nalla RK, Kinney JH, Ritchie RO. 2003. Mechanistic fracture criteria for the failure of human cortical bone. Nat. Mater. 2:164-68

32. Ritchie RO, Buehler MJ, Hansma PK. 2009. Plasticity and toughness in bone. Phys. Today 62:41-47

33. Fratzl P, Gupta HS, Paschalis EP, Roschger P. 2004. Structure and mechanical quality of the collagenmineral nano-composite in bone. 7. Mater. Chem. 14:2115-23

34. Skedros JG, Durand P, Bloebaum RD. 1995. Hypermineralized peripheral lamellae in primary osteons of deer antler: potential functional analogs of cement lines in mammalian secondary bone. F. Bone Miner. Res. 10(Suppl. 1):S441

35. Skedros JG, Holmes JL, Vajda EG, Bloebaum RD. 2005. Cement lines of secondary osteons in human bone are not mineral-deficient: new data in a historical perspective. Anat. Rec. A 286:781-803

36. Burr DB, Schaffler MB, Frederickson RG. 1988. Composition of the cement line and its possible mechanical role as a local interface inhuman compact-bone. F. Biomech. 21:939-45

37. Yeni YN, Norman TL. 2000. Calculation of porosity and osteonal cement line effects on the effective fracture toughness of cortical bone in longitudinal crack growth. F. Biomed. Mater. Res. 51:504-9

38. Weiner S, Traub W, Wagner HD. 1999. Lamellar bone: structure-function relations. F. Struct. Biol. $126: 241-55$

39. Giraud-Guille MM. 1988. Twisted plywood architecture of collagen fibrils in human compact-bone osteons. Calcif. Tissue Int. 42:167-80

40. Ascenzi A, Bonucci E, Generali P, Ripamonti A, Roveri N. 1979. Orientation of apatite in single osteon samples as studied by pole figures. Calcif. Tissue Int. 29:101-5

41. Rho JY, Zioupos P, Currey JD, Pharr GM. 1999. Variations in the individual thick lamellar properties within osteons by nanoindentation. Bone 25:295-300

42. Wagermaier W, Gupta HS, Gourrier A, Burghammer M, Roschger P, Fratzl P. 2006. Spiral twisting of fiber orientation inside bone lamellae. Biointerphases 1:1-5

43. Wagermaier W, Gupta HS, Gourrier A, Paris O, Roschger P, et al. 2007. Scanning texture analysis of lamellar bone using microbeam synchrotron X-ray radiation. F. Appl. Crystallogr. 40:115-20

44. Landis WJ, Hodgens KJ, Arena J, Song MJ, McEwen BF. 1996. Structural relations between collagen and mineral in bone as determined by high voltage electron microscopic tomography. Microsc. Res. Tech. 33:192-202

45. Landis WJ, Hodgens KJ, Song MJ, Arena J, Kiyonaga S, et al. 1996. Mineralization of collagen may occur on fibril surfaces: evidence from conventional and high-voltage electron microscopy and threedimensional imaging. 7. Struct. Biol. 117:24-35

46. Fratzl P, Fratzlzelman N, Klaushofer K, Vogl G, Koller K. 1991. Nucleation and growth of mineral crystals in bone studied by small angle X-ray scattering. Calcif. Tissue Int. 48:407-13

47. Fratzl P, Groschner M, Vogl G, Plenk H, Eschberger J, et al. 1992. Mineral crystals in calcified tissues: a comparative study by SAXS. 7. Bone Miner. Res. 7:329-34

48. Glimcher MJ. 1984. Recent studies of the mineral phase in bone and its possible linkage to the organic matrix by protein bound phosphate bonds. Philos. Trans. R. Soc. Lond. Ser. B 304:479-508

49. Grynpas MD, Bonar LC, Glimcher MJ. 1984. X-ray diffraction radial distribution function studies on bone mineral and synthetic calcium phosphates. F. Mater. Sci. 19:723-36

50. Posner AS. 1985. The mineral of bone. Clin. Orthop. Relat. Res. 200:87-99

51. Rubin MA, Rubin J, Jasiuk W. 2004. SEM and TEM study of the hierarchical structure of C57BL/6J and $\mathrm{C} 3 \mathrm{H} / \mathrm{HeJ}$ mice trabecular bone. Bone 35:11-20

52. Gao HJ, Ji BH, Jager IL, Arzt E, Fratzl P. 2003. Materials become insensitive to flaws at nanoscale: lessons from nature. Proc. Natl. Acad. Sci. USA 100:5597-600

53. Ramachandran GN, Kartha G. 1955. Structure of collagen. Nature 176:593-95

54. Canty EG, Kadler KE. 2002. Collagen fibril biosynthesis in tendon: a review and recent insights. Comp. Biochem. Physiol. A 133:979-85 
55. Kadler KE, Holmes DF, Trotter JA, Chapman JA. 1996. Collagen fibril formation. Biochem. F. 316:1-11

56. Prockop DJ, Kivirikko KI. 1995. Collagens: molecular biology, diseases, and potentials for therapy. Annu. Rev. Biochem. 64:403-34

57. Prockop DJ, Kivirikko KI. 1984. Heritable diseases of collagen. New Engl. 7. Med. 311:376-86

58. Ackbarow T, Chen X, Keten S, Buehler MJ. 2007. Hierarchies, multiple energy barriers, and robustness govern the fracture mechanics of alpha-helical and beta-sheet protein domains. Proc. Natl. Acad. Sci. USA 104:16410-15

59. Keten S, Buehler MJ. 2008. Asymptotic strength limit of hydrogen-bond assemblies in proteins at vanishing pulling rates. Phys. Rev. Lett. 100:198301

60. Keten S, Buehler MJ. 2008. Strength limit of entropic elasticity in beta-sheet protein domains. Phys. Rev. E 78:061913

61. Sun YL, Luo ZP, Fertala A, An KN. 2004. Stretching type II collagen with optical tweezers. F. Biomech. 37:1665-69

62. Buehler MJ. 2008. Nanomechanics of collagen fibrils under varying cross-link densities: atomistic and continuum studies. 7. Mech. Behav. Biomed. Mater. 1:59-67

63. Buehler MJ. 2006. Atomistic and continuum modeling of mechanical properties of collagen: elasticity, fracture, and self-assembly. 7. Mater. Res. 21:1947-61

64. Buehler MJ, Wong SY. 2007. Entropic elasticity controls nanomechanics of single tropocollagen molecules. Biophys. 7. 93:37-43

65. Gautieri A, Buehler MJ, Redaelli A. 2009. Deformation rate controls elasticity and unfolding pathway of single tropocollagen molecules. F. Mech. Behav. Biomed. Mater. 2:130-37

66. Buehler MJ. 2007. Molecular nanomechanics of nascent bone: fibrillar toughening by mineralization. Nanotechnology 18:295102

67. Buehler MJ, Keten S, Ackbarow T. 2008. Theoretical and computational hierarchical nanomechanics of protein materials: deformation and fracture. Prog. Mater. Sci. 53:1101-241

68. Fantner GE, Hassenkam T, Kindt JH, Weaver JC, Birkedal H, et al. 2005. Sacrificial bonds and hidden length dissipate energy as mineralized fibrils separate during bone fracture. Nat. Mater. 4:612-16

69. Craig AS, Birtles MJ, Conway JF, Parry DAD. 1989. An estimate of the mean length of collagen fibrils in rat tail-tendon as a function of age. Connect. Tissue Res. 19:51-62

70. Gupta HS, Wagermaier W, Zickler GA, Aroush DRB, Funari SS, et al. 2005. Nanoscale deformation mechanisms in bone. Nano Lett. 5:2108-11

71. Smith BL, Schaffer TE, Viani M, Thompson JB, Frederick NA, et al. 1999. Molecular mechanistic origin of the toughness of natural adhesives, fibres and composites. Nature 399:761-63

72. Fantner GE, Oroudjev E, Schitter G, Golde LS, Thurner P, et al. 2006. Sacrificial bonds and hidden length: unraveling molecular mesostructures in tough materials. Biophys. F. 90:1411-18

73. Bonar LC, Lees S, Mook HA. 1985. Neutron-diffraction studies of collagen in fully mineralized bone. 7. Mol. Biol. 181:265-70

74. Tai K, Ulm FJ, Ortiz C. 2006. Nanogranular origins of the strength of bone. Nano Lett. 6:2520-25

75. Zioupos P, Currey JD. 1994. The extent of microcracking and the morphology of microcracks in damaged bone. 7. Mater. Sci. 29:978-86

76. Vashishth D, Behiri JC, Bonfield W. 1997. Crack growth resistance in cortical bone: concept of microcrack toughening. 7. Biomech. 30:763-69

77. Vashishth D, Tanner KE, Bonfield W. 2003. Experimental validation of a microcracking-based toughening mechanism for cortical bone. F. Biomech. 36:121-24

78. Vashishth D, Tanner KE, Bonfield W. 2000. Contribution, development and morphology of microcracking in cortical bone during crack propagation. 7. Biomech. 33:1169-74

79. Nalla RK, Kruzic JJ, Kinney JH, Balooch M, Ager JW, Ritchie RO. 2006. Role of microstructure in the aging-related deterioration of the toughness of human cortical bone. Mater. Sci. Eng. C 26:1251-60

80. Koester KJ, Ager JW, Ritchie RO. 2008. The true toughness of human cortical bone measured with realistically short cracks. Nat. Mater. 7:672-77

81. Peterlik H, Roschger P, Klaushofer K, Fratzl P. 2006. From brittle to ductile fracture of bone. Nat. Mater. 5:52-55 
82. Yeni YN, Fyhrie DP. 2003. A rate-dependent microcrack-bridging model that can explain the strain rate dependency of cortical bone apparent yield strength. 7. Biomech. 36:1343-53

83. Nalla RK, Stolken JS, Kinney JH, Ritchie RO. 2005. Fracture in human cortical bone: local fracture criteria and toughening mechanisms. F. Biomech. 38:1517-25

84. Zimmermann EA, Launey ME, Barth HB, Ritchie RO. 2009. Mixed-mode fracture of human cortical bone. Biomaterials 30:5877-84

85. Parsamian GP, Norman TL. 2001. Diffuse damage accumulation in the fracture process zone of human cortical bone specimens and its influence on fracture toughness. F. Mater. Sci. Mater. Med. 12:779-83

86. Nalla RK, Kruzic JJ, Kinney JH, Ritchie RO. 2004. Effect of aging on the toughness of human cortical bone: evaluation by R-curves. Bone 35:1240-46

87. Nalla RK, Kruzic JJ, Ritchie RO. 2004. On the origin of the toughness of mineralized tissue: microcracking or crack bridging? Bone 34:790-98

88. Ritchie RO, Cannon RM, Dalgleish BJ, Dauskardt RH, McNaney JM. 1993. Mechanics and mechanisms of crack-growth at or near ceramic-metal interfaces: interface engineering strategies for promoting toughness. Mater. Sci. Eng. A 166:221-35

89. Cotterell B, Rice JR. 1980. Slightly curved or kinked cracks. Int. 7. Fract. 16:155-69

90. Faber KT, Evans AG. 1983. Crack deflection processes. I. Theory. Acta Metall. 31:565-76

91. Launey ME, Chen P-Y, McKittrick J, Ritchie RO. 2010. Mechanistic aspects of the fracture toughness of elk antler bone. Acta Biomater. 6:1505-14

92. Wegst UGK, Ashby MF. 2004. The mechanical efficiency of natural materials. Philos. Mag. 84:2167-81

93. Zioupos P, Currey JD, Sedman AJ. 1994. An examination of the micromechanics of failure of bone and antler by acoustic emission tests and laser scanning confocal microscopy. Med. Eng. Phys. 16:203-12

94. Vashishth D. 2004. Rising crack-growth-resistance behavior in cortical bone: implications for toughness measurements. 7. Biomech. 37:943-46

95. Krauss S, Fratzl P, Seto J, Currey JD, Estevez JA, et al. 2009. Inhomogeneous fibril stretching in antler starts after macroscopic yielding: indication for a nanoscale toughening mechanism. Bone 44:1105-10

96. Gupta HS, Seto J, Wagermaier W, Zaslansky P, Boesecke P, Fratzl P. 2006. Cooperative deformation of mineral and collagen in bone at the nanoscale. Proc. Natl. Acad. Sci. USA 103:17741-46

97. Ritchie RO, Koester KJ, Ionova S, Yao W, Lane NE, Ager JW. 2008. Measurement of the toughness of bone: a tutorial with special reference to small animal studies. Bone 43:798-812

98. Rauch F, Glorieux FH. 2004. Osteogenesis imperfecta. Lancet 363:1377-85

99. Misof K, Landis WJ, Klaushofer K, Fratzl P. 1997. Collagen from the osteogenesis imperfecta mouse model (oim) shows reduced resistance against tensile stress. 7. Clin. Investig. 100:40-45

100. Gautieri A, Uzel S, Vesentini S, Redaelli A, Buehler MJ. 2009. Molecular and mesoscale mechanisms of osteogenesis imperfecta disease in collagen fibrils. Biophys. 7. 97:857-65

101. Gautieri A, Vesentini S, Redaelli A, Buehler MJ. 2009. Single molecule effects of osteogenesis imperfecta mutations in tropocollagen protein domains. Protein Sci. 18:161-68

102. Turner AN, Rees AJ. 1996. Goodpasture's disease and Alport's syndromes. Annu. Rev. Med. 47:377-86

103. Tryggvason K, Jing Z, Hostikka SL, Shows TB. 1993. Molecular-genetics of Alport syndrome. Kidney Int. 43:38-44

104. Srinivasan M, Uzel SGM, Gautieri A, Keten S, Buehler MJ. 2009. Alport syndrome mutations in type IV tropocollagen alter molecular structure and nanomechanical properties. F. Struct. Biol. 168:503-10

105. Currey JD. 1979. Changes in the impact energy-absorption of bone with age. F. Biomech. 12:459-69

106. Currey JD, Brear K, Zioupos P. 1996. The effects of ageing and changes in mineral content in degrading the toughness of human femora. 7. Biomech. 29:257-60

107. Zioupos P, Currey JD. 1998. Changes in the stiffness, strength, and toughness of human cortical bone with age. Bone 22:57-66

108. Wang X, Shen X, Li X, Agrawal CM. 2002. Age-related changes in the collagen network and toughness of bone. Bone 31:1-7

109. Wang XD, Bank RA, TeKoppele JM, Agrawal CM. 2001. The role of collagen in determining bone mechanical properties. F. Orthop. Res. 19:1021-26

110. Lucksanasombool P, Higgs WAJ, Higgs R, Swain MV. 2001. Fracture toughness of bovine bone: influence of orientation and storage media. Biomaterials 22:3127-32 
111. Knott JF. 1973. Fundamentals of Fracture Mechanics. London: Butterworths

112. Bonfield W. 1987. Advances in the fracture mechanics of cortical bone. F. Biomech. 20:1071-81

113. Phelps JB, Hubbard GB, Wang X, Agrawal CM. 2000. Microstructural heterogeneity and the fracture toughness of bone. 7. Biomed. Mater. Res. 51:735-41

114. Wang XD, Masilamani NS, Mabrey JD, Alder ME, Agrawal CM. 1998. Changes in the fracture toughness of bone may not be reflected in its mineral density, porosity, and tensile properties. Bone 23:67-72

115. Akkus O, Adar F, Schaffler MB. 2004. Age-related changes in physicochemical properties of mineral crystals are related to impaired mechanical function of cortical bone. Bone 34:443-53

116. Brown CU, Yeni YN, Norman TL. 2000. Fracture toughness is dependent on bone location: a study of the femoral neck, femoral shaft, and the tibial shaft. F. Biomed. Mater. Res. 49:380-89

117. Norman TL, Vashishth D, Burr DB. 1995. Fracture toughness of human bone under tension. F. Biomech. 28:309-20

118. Nalla RK, Kruzic JJ, Kinney JH, Ritchie RO. 2005. Mechanistic aspects of fracture and R-curve behavior in human cortical bone. Biomaterials 26:217-31

119. Malik CL, Stover SM, Martin RB, Gibeling JC. 2003. Equine cortical bone exhibits rising R-curve fracture mechanics. F. Biomech. 36:191-98

120. Chen PY, Stokes AG, McKittrick J. 2009. Comparison of the structure and mechanical properties of bovine femur bone and antler of the North American elk (Cervus elaphus canadensis). Acta Biomater. 5:693-706

121. ASTM E1820-08. 2008. Annual Book of ASTM Standards, Vol. 03.0. Metals: Mechanical Testing; Elevated and Low-Temperature Tests; Metallography. West Conshohocken, PA: ASTM Int.

122. Grellmann W.2001. New developments in toughness evaluation of polymers and compounds by fracture mechanics. In Deformation and Fracture Behavior of Polymers, ed. W Grellmann, S Seidler, pp. 3-26. New York: Springer-Verlag

123. Yan JH, Mecholsky JJ, Clifton KB. 2007. How tough is bone? Application of elastic-plastic fracture mechanics to bone. Bone 40:479-84

124. Yan JH, Taskonak B, Platt JA, Mecholsky JJ. 2008. Evaluation of fracture toughness of human dentin using elastic-plastic fracture mechanics. F. Biomech. 41:1253-59

125. Barthelat F, Espinosa HD. 2007. An experimental investigation of deformation and fracture of nacremother of pearl. Exp. Mech. 47:311-24

126. Yang QD, Cox BN, Nalla RK, Ritchie RO. 2006. Re-evaluating the toughness of human cortical bone. Bone 38:878-87 